\title{
There is no evidence to support literature claims of direct electron transfer (DET) for native glucose oxidase (GOx) at carbon nanotubes or graphene
}

\author{
Philip N. Bartlett ${ }^{\mathrm{a}}$ and Firas A. Al-Lolage $\mathrm{e}^{\mathrm{a}, \mathrm{b}}$ \\ ${ }^{a}$ Chemistry, University of Southampton, Southampton, SO17 1BJ, UK \\ ${ }^{\mathrm{b}}$ Department of Chemistry, College of Science, University of Mosul, Mosul, Iraq
}

\begin{abstract}
It is widely claimed that native GOx undergoes direct electron transfer (DET) at nanostructured electrodes. In this paper we argue that the vast majority, if not all, of these claims are incorrect. We present results for GOx adsorbed on MWCNTs, a typical nanostructured electrode. We show that the surface redox peaks usually attributed to DET to GOx actually arise from flavin, and possibly catalase, impurities present in the as supplied commercial enzyme that are adsorbed at the electrode surface. We show that the observed response to glucose is due to enzymatic activity, but not electroactivity, of adsorbed GOx that catalyses the reaction of D-glucose with dissolved oxygen leading to a decrease in the oxygen reduction current that correlates with the glucose concentration.
\end{abstract}

\section{Introduction}

Glucose oxidase from Aspergillus niger (E.C. 1.1.3.4) is the most heavily studied redox enzyme for electrochemical applications with studies dating back to the seminal work of Clark and Lyons in 1962 on the original enzyme electrodes [1, 2]. The reasons for its popularity are several fold. It is readily available and highly active, it is a very stable and robust enzyme and, most significantly, the monitoring of its substrate, $\beta$-D-glucose, is vital for the management of diabetes. Consequently, an enormous number of publications on electrochemical glucose biosensors have appeared since Clark's initial paper. These electrochemical glucose biosensors can be divided into three classes. So called "first generation" [3] glucose biosensors, like the Clark work, in which either a co-reactant (oxygen) or product (hydrogen peroxide) of the natural enzymatic reaction is measured electrochemically; "second generation" glucose biosensors where an artificial, freely diffusing redox mediator replaces oxygen in the enzymatic reaction, the notable example 
being the ground breaking work of Cass [4] using ferrocenes; and "third generation" glucose biosensors in which direct electrochemical oxidation of the flavin active site of glucose oxidase occurs. It is this last case that we consider in this paper. Our contention is that the vast majority of publications in the literature which claim such direct electron transfer (DET) to glucose oxidase (GOx) there is no evidence to support the claim and that the results support an entirely different explanation.

Glucose oxidase from Aspergillus niger is a homodimer [5, 6]. The enzyme is heavily glycosilyated. Its molecular weight is around $160 \mathrm{kDa}$ depending on the precise level of glycosylation. The enzyme is highly specific for the oxidation of the $\beta$-anomer of D-glucose and the reaction occurs via a "ping-pong" mechanism in which one of the oxidised flavin active sites (FAD) in the homodimer reacts with the substrate to give the reduced flavin $\left(\mathrm{FADH}_{2}\right)$ and the product gluconolactone (which undergoes a subsequent hydrolysis in neutral solution to gluconic acid).

$\beta$-D-glucose $\left(\mathrm{C}_{6} \mathrm{H}_{12} \mathrm{O}_{6}\right)+\mathrm{GOx}(\mathrm{FAD}) \rightarrow$ D-glucono-1,5-lactone $\left(\mathrm{C}_{6} \mathrm{H}_{10} \mathrm{O}_{6}\right)+\mathrm{GOx}\left(\mathrm{FADH}_{2}\right)$

The reduced active site in the homodimer is then regenerated by reaction with oxygen.

$\mathrm{GOx}\left(\mathrm{FADH}_{2}\right)+\mathrm{O}_{2} \rightarrow \mathrm{GOx}(\mathrm{FAD})+\mathrm{H}_{2} \mathrm{O}_{2}$

The two flavin active sites are buried deeply within the structure of the homodimer and there is no evidence for redox communication between them [6].

All of the early work on glucose biosensors was carried out without the knowledge of the crystal structure of the enzyme. The structure was finally published by Hecht in 1993 [6, 7], many years after the successful commercialization of electrochemical glucose biosensors. From the crystal structure, Fig. 1, we can see that access to the flavin active site is down a narrow channel formed at the interface between the two homodimers. This structure serves to insulate the flavin active sites from non-specific electron transfer with redox species in the biological system and controls the local environment around the flavin ensuring high selectivity, for example, the $\beta$-anomer of $\mathrm{D}$-glucose is oxidised 150 times more rapidly than the $\alpha$-anomer and the enzyme shows only low activity with closely related sugars, such as 2 deoxy-D-glucose [8] and no activity with L-glucose. 
From the crystal structure, Fig. 1, we can see that the flavin active sites are at least $1.7 \mathrm{~nm}$ from the surface of the protein. The crystal structure is for the de-glycosilylated enzyme so, in reality this distance will be somewhat larger for the native, glycosilyated enzyme where the carbohydrate makes up 16-25\% of the mass of the enzyme [9-11]. There have been many studies of electron transfer through proteins, notably the work of the groups of Gray and of Dutton [12-15]. Although they may differ in some details, these studies all agree that the rate of electron transfer through the protein falls off exponentially with distance and that fast electron transfer (sufficient to sustain substrate limited currents) through proteins is restricted to around $0.8 \mathrm{~nm}$ or less, with the rate of DET decreasing by around $10^{4}$ when the distance is increased from 0.8 to $1.7 \mathrm{~nm}$ [16]. This makes the observation of DET for glucose oxidase rather unlikely.

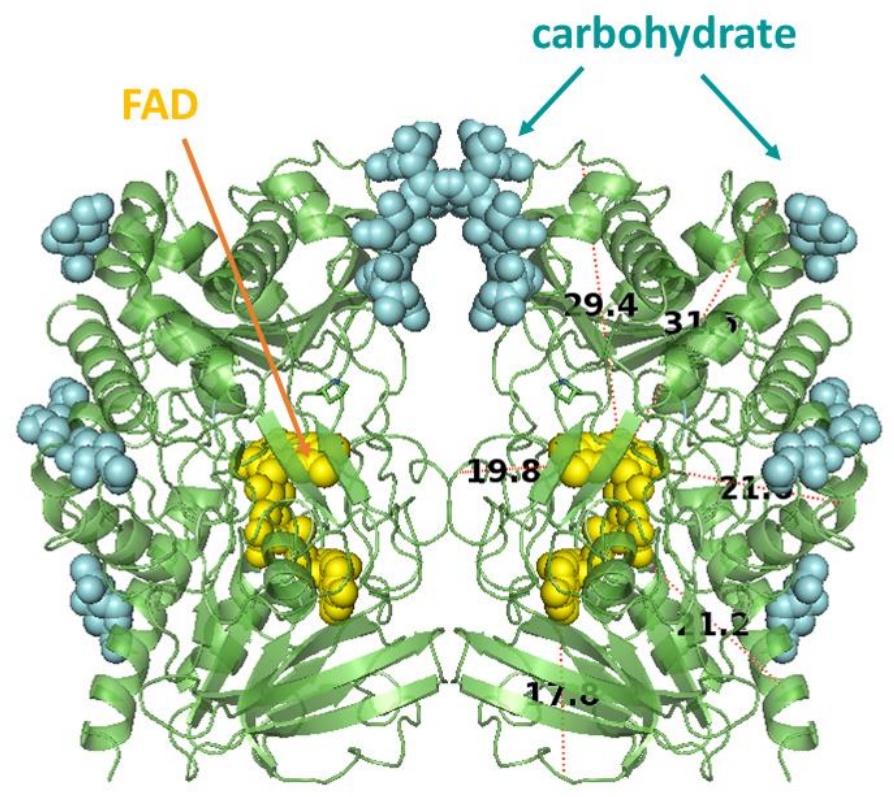

Fig. 1 Representation of secondary structure of GOx. The image was obtained with PyMol software, PyMol visualizations are based on the crystal structure of GOx from Aspergillus niger, PDB code 1 gal http://www.rcsb.org/pdb/explore/explore.do?structureId=1GAL

Despite this distance problem DET has been widely claimed in the literature for glucose oxidase adsorbed, or otherwise immobilised, on a range of carbon and other nanomaterials such and carbon nanotubes and more recently graphene with other additives, see Table S1 for a selection of over 100 examples. The claimed DET of GOx at these nanocarbon materials is often attributed to some "special", but not clearly specified, properties of the nanocarbon material or possibly some particular interaction of the enzyme and the carbon nanotubes that allow the CNTs to "plug into" the enzyme to access the active site, or for the GOx to 
partially unfold enabling the charge transfer between the FAD cofactor and CNT. DET for GOx at different nanomaterials is discussed in a number of recent reviews [17-21].

The typical pieces of experimental evidence presented to support these claims of DET for glucose oxidase are (see Table S1 for examples): i) the appearance of a pair of surface bound redox peaks at around $-0.46 \mathrm{~V} v s$. SCE at $\mathrm{pH} 7$, assumed to be the flavin in the active enzyme, and, ii) changes in the current on addition of glucose that correlate with the glucose concentration. Many of these claims of DET for glucose oxidase are supported by an argumentum ad populum, or "me too" argument, that the data presented closely resemble that already in the literature in papers that claim DET.

In this paper we examine critically the experimental evidence and point out the fallacies and errors in logic that are commonplace in the literature when DET of glucose oxidase is claimed. To do this we present experimental results for the study of glucose oxidase adsorbed on multiwall carbon nanotubes (MWCNTs). Glucose oxidase and MWCNTs are not simple, pure, well defined, reagents; both can contain significant amounts of impurities, and both can be subject to batch to batch variations. In this work we have used 4 different suppliers/sources of glucose oxidase and 2 of MWCNTs. The results we will show are essentially identical to those in many (over 100) papers in the literature that claim DET to GOx both for CNTs and graphene. We will show how these results can be explained and in so doing suggest some tests that would need to be met to support any serious claim of DET for GOx.

\section{Experimental}

\subsection{Chemicals}

Glucose oxidase type X-S (EC 1.1.3.4, from Aspergillus niger, 228 U/mg solid), glucose oxidase type VII (EC 1.1.3.4, from Aspergillus niger, $100 \mathrm{U} / \mathrm{mg}$ solid), glucose oxidase type II (EC 1.1.3.4, from Aspergillus niger, $17 \mathrm{U} / \mathrm{mg}$ solid) and catalase (CAT) from bovine liver 20-50 kU / mg were purchased from Sigma. Glucose oxidase type GO3A, batch 614Z, (EC 1.1.3.4, from Aspergillus niger, $335 \mathrm{U} / \mathrm{mg}$ protein), GOx / CAT ratio $\geq 27500$ was purchased from BBI Solutions, UK, All enzymes were stored at $-20^{\circ} \mathrm{C}$ when not in use. Multi-walled carbon nanotubes carboxylic acid functionalized (> 8\% carboxylic acid functionalized avg., $9.5 \mathrm{~nm}$ in diameter and $1.5 \mu \mathrm{m}$ in length) were purchased from Aldrich. Multi-walled carbon nanotubes (30 $\pm 10 \mathrm{~nm}$ in diameter and $1-5 \mu \mathrm{m}$ in length) were purchased from NanoLab, 
Inc. All other chemicals were of analytical grade and used without further purification. All solutions were prepared using deionized Millipore-Q water $(18.2 \mathrm{M} \Omega \mathrm{cm})$.

\subsection{Instrumentation}

All voltammetric measurements were carried out using an Autolab PGSTAT30 Potentiostat/Galvonostat (Ecochemie). The three-electrode system consists of a working electrode (glassy carbon) a reference electrode (SCE) and a counter electrode (platinum gauze). Electrodes used for the experiments were $3 \mathrm{~mm}$ diameter $\left(0.071 \mathrm{~cm}^{2}\right)$ glassy carbon (GC) disc electrodes (HTW Hochtemperatur - Werkstoffe GMBH, Germany), sealed in glass tubes and contacted using copper wire and melted indium (Aldrich). EDS spectra were recorded over $60 \mathrm{~s}$ with an accelerating voltage of $20 \mathrm{kV}$ using a Jeol JSM 6500F field emission scanning electron microscope.

\subsection{Glassy carbon (GC) electrode preparation}

Before the experiment, the glassy carbon electrodes were polished with 1 and $0.3 \mu \mathrm{m}$ alumina slurries on polishing cloth pads (Buehler). The polished GC electrodes were sonicated in deionized water for $7 \mathrm{~min}$ and dried in a stream of argon for $1 \mathrm{~min}$. They were then sonicated in ethanol for $13 \mathrm{~min}$ and dried in a stream of argon for $1 \mathrm{~min}$. The cleaned electrodes were covered with pipette tips until used.

\subsection{Fabrication of GC/MWCNT electrode and immobilization of GOx}

$10 \mathrm{mg}$ of MWCNTs were dispersed in $10 \mathrm{~mL}$ dimethylformamide (DMF) with the aid of ultra-sonication to give a $1 \mathrm{mg} \mathrm{mL}^{-1}$ black suspension. The MWCNT modified glassy carbon (GC/MWCNT) electrode was prepared by drop casting of $5 \mu \mathrm{L}$ of the MWCNT dispersion onto the cleaned surface of GC. Then, the modified GC electrode was allowed to dry at ambient temperature before use. To immobilize GOx, the MWCNT/GC electrode was incubated in a solution of $1 \mathrm{kU}$ GOx (corresponding to a $1 \mathrm{mM}$ solution of enzyme) dissolved in $1 \mathrm{~mL}$ of $0.1 \mathrm{M}$ phosphate buffer solution ( $\mathrm{pH}$ 6.8) for $12 \mathrm{~h} .1 \mathrm{U}$ of GOx will oxidize 1.0 $\mu$ mole of $\beta$-D-glucose to D-gluconolactone and $\mathrm{H}_{2} \mathrm{O}_{2}$ per minute at $\mathrm{pH} 5.1$ and $35{ }^{\circ} \mathrm{C}$.

\subsection{Determination of the $\mathrm{pH}$ dependent redox potential of glucose oxidase}

Cyclic voltammetry measurements for GC/MWCNTs/GOx electrodes were carried out in 0.1 $\mathrm{M}$ buffers, $\mathrm{pH}$ values $(4.5$ - 8.5). Measurements were done in buffer (depending on $\mathrm{pH}$ sodium citrate, sodium phosphate, or tris (hydroxymethyl) aminomethane (TRIS)-buffer were 
used) with $0.1 \mathrm{M}$ potassium chloride and $5 \mathrm{mM}$ magnesium chloride. Buffer solutions were deoxygenated by purging with $\mathrm{Ar}$ gas for at least $30 \mathrm{~min}$ prior to electrochemical measurements.

\section{Results}

\subsection{Electrochemistry of carbon nanotube electrodes with adsorbed GOx}

Fig. 2 shows cyclic voltammograms obtained at bare glassy carbon (GC) (a), glassy carbon with adsorbed glucose oxidase (GC/GOx) (b), glassy carbon drop coated with carboxylate functionalised multiwall carbon nanotubes (GC/MWCNT) (c), and glassy carbon drop coated with multiwall carbon nanotubes and adsorbed glucose oxidase (GC/MWCNT/GOx) (d) recorded in deoxygenated $0.1 \mathrm{M}$ phosphate buffer solution, $\mathrm{pH}$ 6.8. The glucose oxidase was adsorbed on the GC and GC/MWCNT electrodes by incubation for $12 \mathrm{~h}$ in a solution containing $1 \mathrm{kU}$ of GOx dissolved in $1 \mathrm{~mL}$ of $0.1 \mathrm{M}$ phosphate buffer solution ( $\mathrm{pH} 6.8$ ).

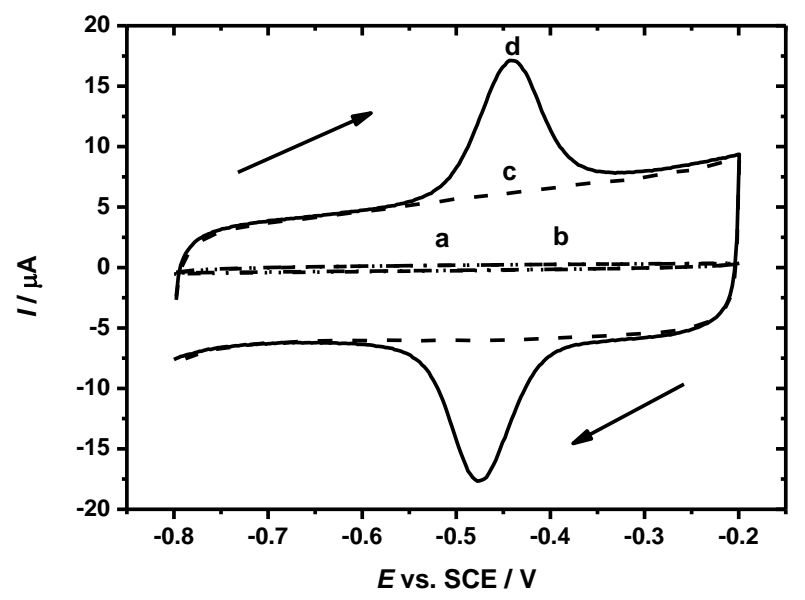

Fig. 2. Cyclic voltammograms of different electrodes in $0.1 \mathrm{M}$ deoxygenated PBS (pH 6.8) at the scan rate of $60 \mathrm{mV} \mathrm{s}^{-1}$ (a) Bare GC, (b) GC/GOx, (c) GC/MWCNT and (d) GC/MWCNT/GOx. The GC/MWCNT electrode was prepared by drop casting of $5 \mu \mathrm{L}$ of 1 $\mathrm{mg} \mathrm{mL} \mathrm{m}^{-1} \mathrm{MWCNT}$ (carboxylic acid functionalized) dispersion onto the cleaned surface of GC. GOx was immobilized using incubation in a solution of $1 \mathrm{kU} \mathrm{mL}^{-1} \mathrm{GOx}$ in $0.1 \mathrm{M}$ phosphate buffer solution ( $\mathrm{pH} 6.8)$ for $12 \mathrm{~h}$.

In the absence of adsorbed GOx the voltammetry of the bare GC electrode (a) and the GC/MWCNT multiwall carbon nanotube electrode (c) are featureless although it is notable 
that the background double layer charging current is significantly larger for the GC/MWCNT electrode due to the much greater surface area - the surface area of the GC / MWCNT electrode is $c a$. 100 times more than that of the bare GC electrode. An estimated area of $c a$. $14 \mathrm{~cm}^{2}$ was obtained using the method described by Peigney [22] for $9.5 \mathrm{~nm}$ MWCNTs with 7-9 walls. For the two electrodes after incubation in the GOx solution there is a very clear pair of redox peaks in the case of the GC/MWCNT/GOx electrode (d) but no obvious change for the GC electrode (compare (a) and (b)). For the pair of redox peaks at the GC/MWCNT/GOx electrode at $60 \mathrm{mV} \mathrm{s}^{-1}$ the formal potential $\left(E^{\circ}\right)$ is $c a .-0.459 \mathrm{~V} v$ s. SCE with a peak-to-peak separation $\left(\Delta E_{\mathrm{p}}\right)$ of $0.021 \mathrm{~V}$, the cathodic and anodic peak currents and charges are approximately equal.

The results shown in Fig. 2 are essentially identical to those in the literature reported for GOx at carbon nanotube electrodes and other types of high surface nanostructured electrode such as graphene and are frequently taken as evidence of direct electron transfer to flavin in the redox active site of the enzyme (for examples see Table S1).

\subsection{Effect of scan rate on voltammetry of GC/MWCNT/GOx}

To investigate the electrochemistry of the adsorbed species experiments were carried out at different scan rates and two types of multiwalled carbon nanotube were used: pure carboxylate functionalised MWCNTs and impure MWCNTs (the metallic impurities in these MWCNTs are discussed below). Fig. 3 and 4 show the voltammetry. The voltammetry on the two different electrodes is very similar. In both cases the redox peak currents $\left(I_{\mathrm{pa}}\right.$ and $\left.I_{\mathrm{pc}}\right)$ increase linearly with increasing scan rates from 10 to $1000 \mathrm{mV} \mathrm{s}^{-1}$ indicative of a surface adsorbed redox species. The peak-to-peak separation $\left(\Delta E_{\mathrm{p}}\right)$ increase linearly with increasing scan rates with the cathodic $\left(E_{\mathrm{pc}}\right)$ and anodic $\left(E_{\mathrm{pa}}\right)$ peak potentials moving in positive and negative directions respectively. For the carboxylate functionalised MWCNTs the redox charge is $4.3 \mu \mathrm{C}$ and for the impure MWCNTs $4.2 \mu \mathrm{C}$. Assuming a surface area of $14 \mathrm{~cm}^{2}$ and a two electron process this corresponds to a coverage of around $1.5 \times 10^{-12} \mathrm{~mol} \mathrm{~cm}^{-2}$. 

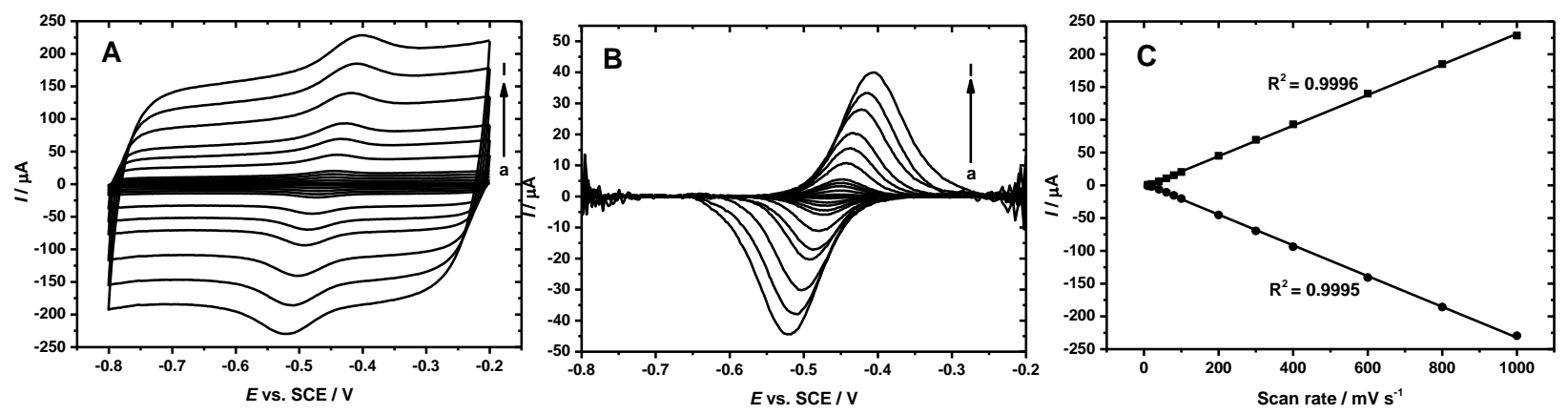

Fig. 3. (A) Cyclic voltammograms of GC/MWCNT/GOx electrode in deoxygenated $0.1 \mathrm{M}$ PBS (pH 6.8) at different scan rates (from (a) to (1): 10, 20, 40, 60, 80, 100, 200, 300, 400, 600,800 and $1000 \mathrm{mV} \mathrm{s}^{-1}$ ). (B) After background current subtraction. (C) Shows the plot of peak currents against scan rate. The electrode was prepared as in Fig. 2.
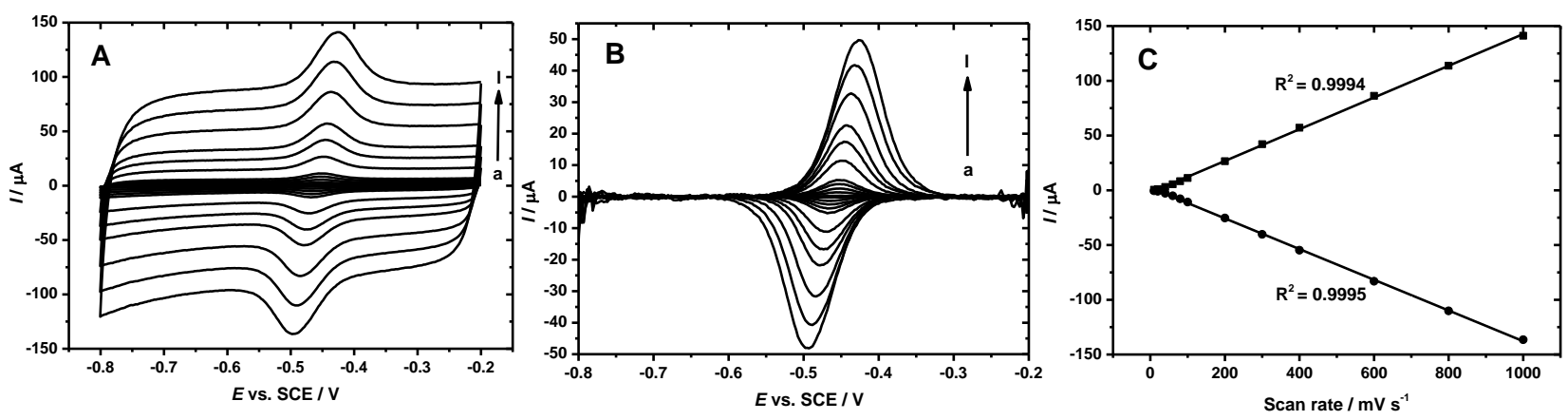

Fig. 4. (A) Cyclic voltammograms of GC/MWCNT/GOx electrode in deoxygenated $0.1 \mathrm{M}$ PBS (pH 6.8) at different scan rates (from (a) to (1): 10, 20, 40, 60, 80, 100, 200, 300, 400, $600,800,1000 \mathrm{mV} \mathrm{s}^{-1}$ ). (B) After background current subtraction. (C) Shows the plot of peak currents against scan rate. The electrode was prepared as in Fig. 2.

Fig. 5 shows

Laviron

"trumpet plots"

two sets of

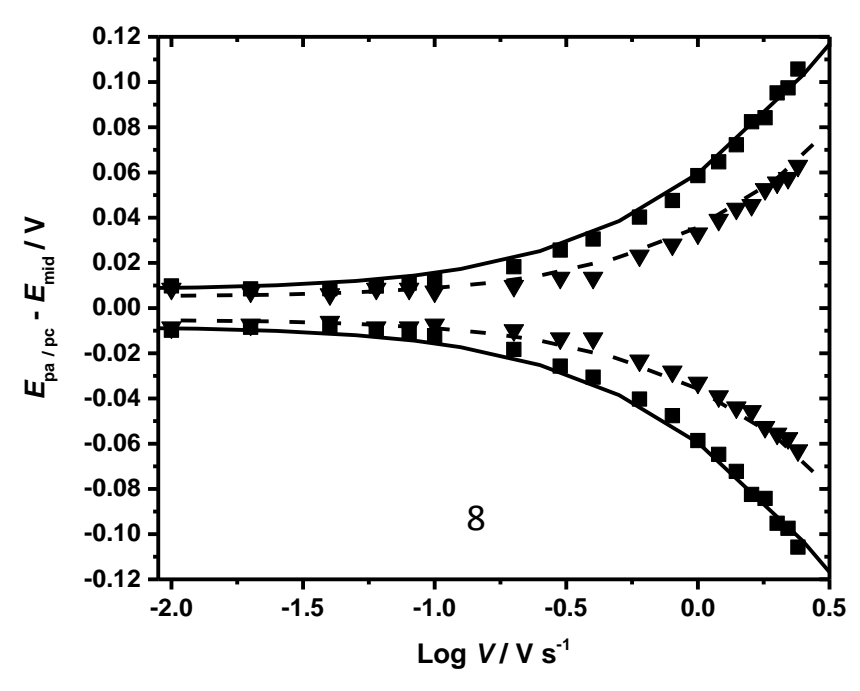

[23] for the 
voltammograms. These trumpet plots can be analysed to extract estimates of the electron transfer kinetics for the adsorbed species, however there are some complications in this analysis because the original Laviron equations refer to a 1e reaction and because the results in the voltammetry can be distorted by iR drop [24] that will increase the peak separations, particularly at high scan rate when the peak current is largest. In addition, in common with results for many surface redox couples, the trumpet plots show a residual peak separation at low scan rate that is not accounted for in the Laviron theory [25-27].

Fig. 5 Plots of $E_{\mathrm{pa} / \mathrm{pc}}-E_{\text {mid }}$ against $\log$ scan rate for GC/MWCNT/GOx electrodes in deoxygenated 0.1 M PBS ( $\mathrm{pH} 6.8$ ) at different scan rates $\left(10-2400 \mathrm{mV} \mathrm{s}^{-1}\right.$ ). The lines are the calculated using the theoretical expression of Laviron with $\alpha=0.6$ for anodic and cathodic curves. The electrodes were prepared as in Fig. 2. Full line, squares: using pure carboxylic acid functionalized MWCNTs; broken line, triangles: using impure MWCNTs.

To obtain estimates for the electron transfer rate constants the data were fitted to working curves for the peak separation at different scan rates generated using the expressions for $E_{\mathrm{pa}}$ and $E_{\mathrm{pc}}$ calculated by numerical solution of the Laviron model [23] following the approach described by Honeychurch [28]. This gives rate constants of $6.6 \mathrm{~s}^{-1}$ and $10.5 \mathrm{~s}^{-1}$ for the carboxylate functionalised pure MWCNTs and the impure MWCNTs respectively.

Independent of the precise details of the Laviron analysis it is clear that the electron transfer kinetics for the surface bound redox species are fast (at least $6 \mathrm{~s}^{-1}$ ) and this is inconsistent with long range electron transfer over $1.7 \mathrm{~nm}$ as would be required by the crystal structure of GOx. Thus although these redox peaks appear in a region that might be consistent with 
oxidation/reduction of the flavin in the GOx active site it seems much more likely that there is some other explanation for the voltammetry.

\subsection{Denaturation using guanidine hydrochloride}

One piece of evidence that has been proposed in the literature [29, 30] to support the conclusion that the redox peaks are due to DET to GOx is the effect of guanidine hydrochloride. It is known that guanidine hydrochloride at high concentration can readily dissociate FAD from the active site of GOx and/or denature GOx and displace it from the electrode surface [29, 31]. It is also known that high concentrations of guanidine hydrochloride have little effect of FAD directly adsorbed at electrode surfaces [29, 30]. Fig. 6 shows the results of this type of experiment for our GC/MWCNT/GOx electrode. After incubation of the electrode in $3 \mathrm{M}$ guanidine hydrochloride solution for $12 \mathrm{~h}$, the redox peak has approximately halved in size. Thus, these results appear to support the idea that the redox peaks are due to DET to GOx. However, the situation is more complex. High concentrations of guanidine hydrochloride are known to denature proteins [32]. We therefore carried out a control experiment in which we incubated the GC/MWCNT electrode with flavin and human serum albumin, a $65 \mathrm{kDa}$ heart shaped, soluble protein with no redox centres of its own [33]. The results are shown in Fig. 7.
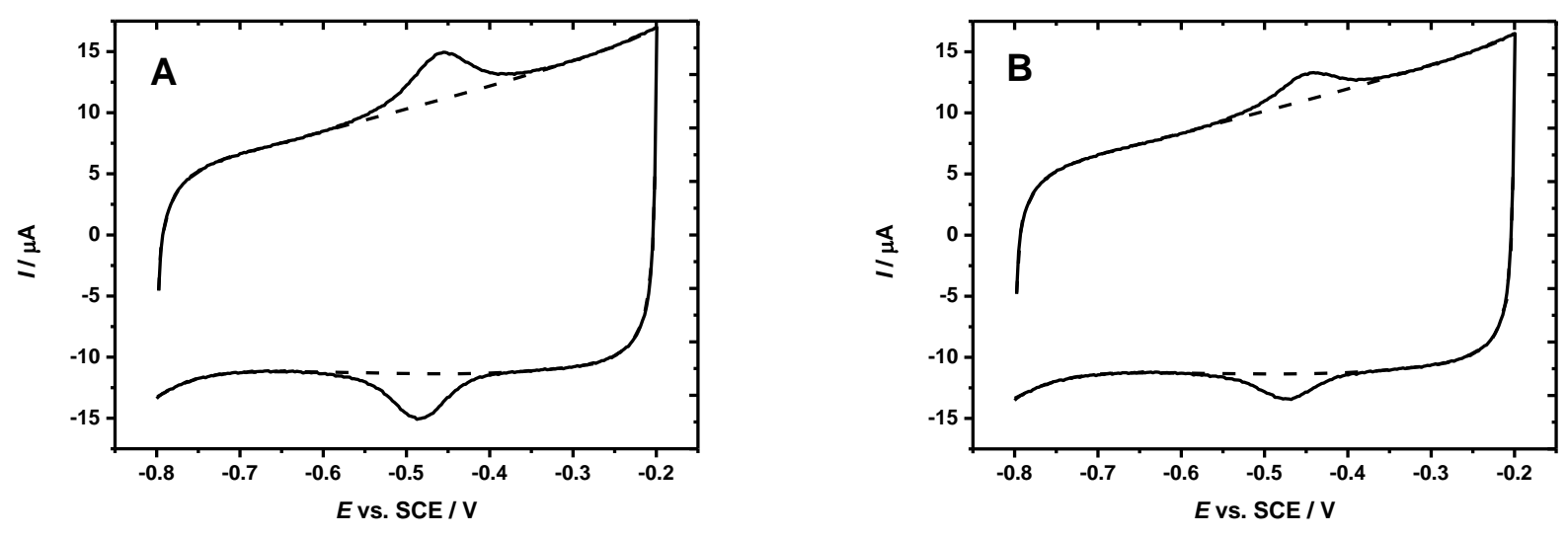

Fig. 6. Cyclic voltammograms in $0.1 \mathrm{M}$ deoxygenated PBS (pH 6.8) at a scan rate of $60 \mathrm{mV}$ $\mathrm{s}^{-1}$ for the GC /MWCNT /GOx electrode (dashed lines) before (A) and after (B) incubation in $3 \mathrm{M}$ guanidine hydrochloride solution for $12 \mathrm{~h}$, the solid lines are the corrected baseline. The GC/MWCNT electrode was prepared as in Fig. 2 using MWCNT (carboxylic acid functionalized).

In this case, the GC/MWCNT electrode was immersed in a mixture of human serum albumin and FAD for $4 \mathrm{~h}$ and then the electrode was incubated in $3 \mathrm{M}$ guanidine hydrochloride for 12 
h. Fig. 7A shows the voltammetry for the GC/MWCNT/ (albumin + FAD) electrode before incubation in $3 \mathrm{M}$ guanidine hydrochloride solution. Surface redox peaks for the adsorbed flavin are clearly visible around $-0.454 \mathrm{~V}$ vs. SCE. After incubation with guanidine hydrochloride these peaks are significantly reduced, again nearly half of the redox peak has disappeared. Thus we cannot conclude, based on the effect of guanidine hydrochloride, that that the redox peaks must be associated with DET to GOx. They could as readily be explained as due to free flavin at the electrode surface that is significantly reduced in coverage when incubated with guanidine hydrochloride when a protein, GOx or human serum albumin, is also present on the surface. Most probably this is caused by co-desorption of the flavin with the denatured protein.
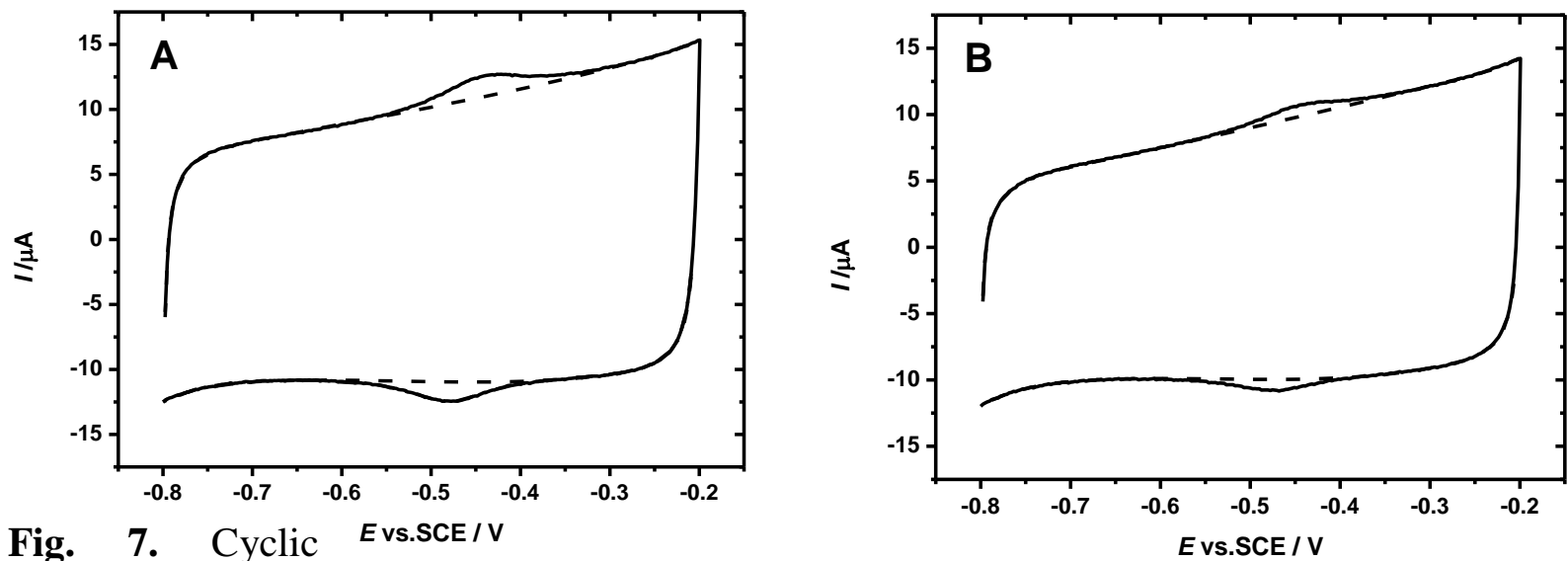

Fig. 7. Cyclic Evs.SCE/v voltammograms in $0.1 \mathrm{M}$ deoxygenated PBS ( $\mathrm{pH} \mathrm{6.8)} \mathrm{at} \mathrm{a} \mathrm{scan} \mathrm{rate} \mathrm{of} 60 \mathrm{mV} \mathrm{s}^{-1}$ for the GC / MWCNT / albumin + FAD electrode (dashed lines) before (A) and after (B) incubation in 3 $\mathrm{M}$ guanidine hydrochloride solution for $12 \mathrm{~h}$, the solid lines are the corrected baseline. The GC/MWCNT electrode was prepared as in Fig. 2 using MWCNT (carboxylic acid functionalized). (Albumin + FAD) was immobilized using incubation in a solution of $0.6 \mathrm{x}$ $10^{-6} \mathrm{M}$ FAD in $1.9 \mathrm{mg} / \mathrm{ml}$ human serum albumin for $4 \mathrm{~h}$.

\subsection{Adsorbed flavin}

An obvious candidate for the adsorbed redox species seen on the GC/MWCNT/GOx electrodes is flavin adsorbed directly on the electrode surface, but where could this free flavin come from? There are two obvious sources, free flavin as an impurity in the original enzyme solution [34-36] or flavin that dissociates from the enzyme during the incubation of the electrode with the enzyme. The flavin in GOx is known to be strongly bound and not to be removed by dialysis at neutral $\mathrm{pH}$ [37] but it is also know that flavin is adsorbed to the enzyme [34]. 
In order to investigate this possibility we carried out an experiment in which the GC electrode was covered by a dialysis membrane (Sigma No. D9777) during incubation with the GOx solution. The GC electrode was used rather than the GC/MWCNT electrode in order to avoid the dialysis membrane displacing the drop coated MWCNTs. The dialysis membrane has a typical molecular weight cut-off of 14,000 Dalton. Therefore free FAD can readily penetrate through the membrane but GOx, with a relative molar mass around $160 \mathrm{kD}$, cannot. Fig. 8 shows the results. For the GC electrode incubated with the freshly prepared solution of assupplied, commercial GOx (Fig. 8A) weak anodic and cathodic peaks around $-0.452 \mathrm{~V} v s$. SCE can be seen. For the dialysis membrane covered GC incubated in an aged solution of the same GOx (Fig. 8B) the same redox peaks are clearly visible but in this case the intensity is larger. The adsorbed redox peaks in these experiments are significantly less prominent than those at the GC/MWCNT electrodes (compare Fig. 2 and 8) but this is because, first, the dialysis membrane acts as a diffusional barrier to the flavin reaching the GC surface and, second, the area of the GC electrode is much less than that for the GC/MWCNT electrode. Nevertheless the experiment clearly shows that free flavin is present in solution, that it is there in greater amounts in the aged enzyme solution, indicating that the flavin does dissociate from the GOx over time [34], and that it adsorbs at the electrode surface to give redox peaks in the same region as seen for the GC/MWCNT/GOx electrode.
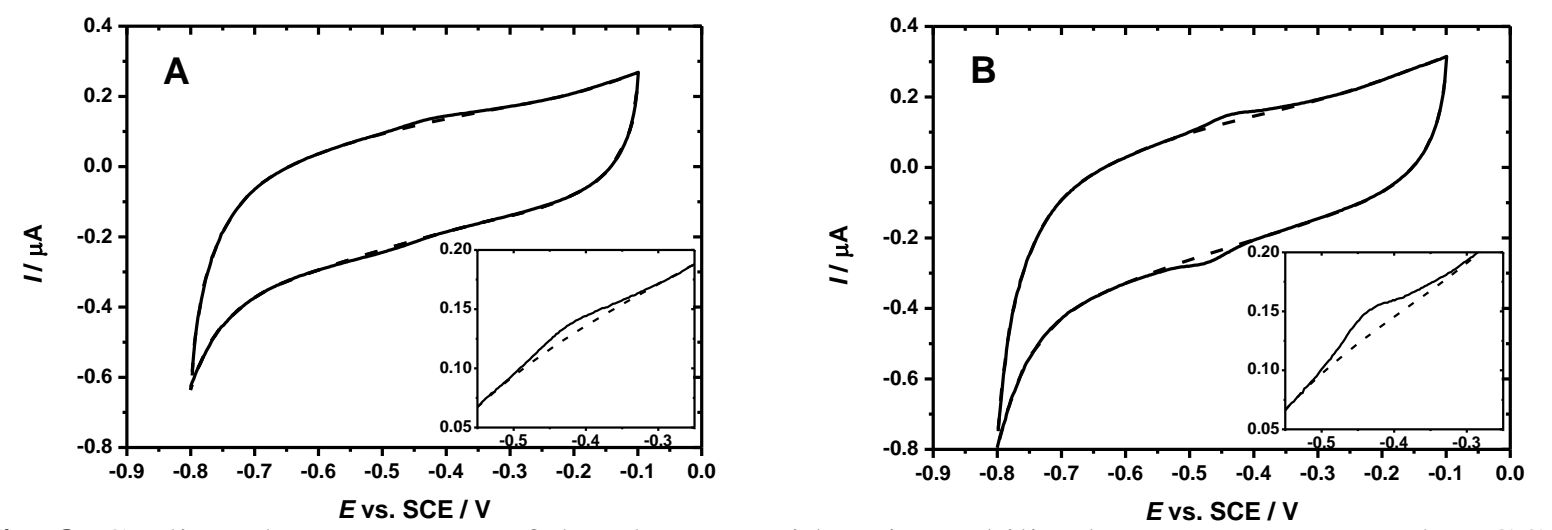

Fig. 8. Cyclic voltammograms of the glucose oxidase immobilised on the GC electrode covered by dialysis membrane in $0.1 \mathrm{M}$ PBS ( $\mathrm{pH} \mathrm{6.8)} \mathrm{at} \mathrm{a} \mathrm{scan} \mathrm{rate} \mathrm{of} 70 \mathrm{mV} \mathrm{s}^{-1}$ (dashed lines), the solid lines are the calculated baselines. The GC electrode was incubated in a solution of $1 \mathrm{kU} \mathrm{mL}^{-1} \mathrm{GOx}$ in $0.1 \mathrm{M}$ phosphate buffer solution ( $\mathrm{pH}$ 6.8) for $3 \mathrm{~h}$. (A) The GOx solution was freshly prepared, (B) the glucose oxidase solution was prepared $48 \mathrm{~h}$ prior to incubation.

\subsection{The effect of catalase}


Free flavin is not the only impurity in commercial samples of GOx that can complicate interpretation of the voltammetry. A survey of seventy papers in the literature on GOximmobilised electrodes shows that $c a$. $90 \%$ of these papers used glucose oxidase obtained from Sigma Aldrich which was used "as received" with no further purification. Either low yield or parallel production of catalase (CAT) are the main problems in the manufacture of glucose oxidase [38]. According to the supplier's specification sheets the different grades of GOx have different ratios of GOx to catalase (CAT). For Sigma type VII GOx, which was used in about $17 \%$ of these papers, the ratio of GOx to CAT is about 15; for Sigma type X-S GOx, which was used in approximately $27 \%$ of these papers, the ratio is about 30 ; and for Sigma type II, which was used by $46 \%$ of these papers, the ratio is about 7.5. On the other hand, nearly $10 \%$ of the papers used a pure glucose oxidase acquired from other suppliers.

Catalase (EC 1.11.1.6) is a tetrameric enzyme that catalyses the decomposition of hydrogen peroxide and peroxidatively oxidises alcohol, formate or nitrate using hydrogen peroxide [39]. The four subunits of the enzyme are identical with a relative molecular mass of $57 \mathrm{kDa}$. Each sub-unit contains a high spin ferriprotoporphryin IX redox group [40, 41]. Numerous groups have studied the electrochemistry of catalase adsorbed on electrode surfaces [42]. Adsorption of catalase at nanostructured electrode surfaces such as carbon nanotube electrodes shows evidence of a well defined pair of surface redox peaks at around $-0.47 \mathrm{~V} v s$ SCE $[43,44]$. These redox peaks shift by around $59 \mathrm{mV} \mathrm{pH}^{-1}$ and are close to the redox potential expected for the heme $\mathrm{Fe}(\mathrm{II}) / \mathrm{Fe}(\mathrm{III})$ redox centre [45].

Fig. 9 shows the cyclic voltammogram of GC/MWCNT/CAT electrode in $0.1 \mathrm{M}$ deoxygenated PBS ( $\mathrm{pH}$ 6.8). The electrode was prepared in exactly the same way as the GC/MWCNT/GOx electrode but by incubating the electrode in CAT instead of with GOx using a solution of $1 \mathrm{kU}$ CAT dissolved in $0.1 \mathrm{M}$ phosphate buffer solution ( $\mathrm{pH}$ 6.8) for $12 \mathrm{~h}$. A pair of well-defined surface redox peaks can be observed for the GC/MWCNT/CAT electrode. The anodic peak potential $\left(E_{\mathrm{pa}}\right)$ and the cathodic peak potential $\left(E_{\mathrm{pc}}\right)$ of the redox peaks of the CAT modified electrode are located at -0.43 and $-0.47 \mathrm{~V}$, respectively. Thus, the formal potential calculated was $-0.45 \mathrm{~V} \pm 1 \mathrm{mV} v s$. SCE and the peak potential separation $\left(\Delta E_{\mathrm{p}}\right)$ was found to be $46 \mathrm{mV}$ at $60 \mathrm{mV} \mathrm{s}^{-1}$. The charge associated with this redox process $(5.0 \mu \mathrm{C})$ is very similar to that seen for the adsorbed GOx in Fig. 3 and 4. These results are very similar to those in the literature for catalase [42-44]. It is notable that the formal potential for the surface redox couple on the GC/CNT/GOx electrode prepared using GOx from Sigma (Fig. 2) was also $-0.46 \mathrm{~V} v s$. SCE. 


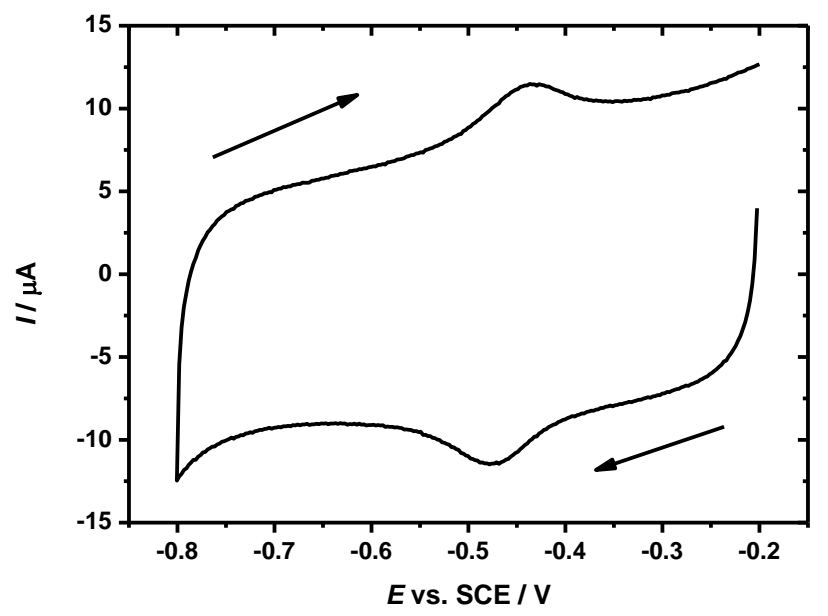

Fig. 9. Cyclic voltammograms of GC/MWCNT/CAT electrode in $0.1 \mathrm{M}$ deoxygenated PBS (pH 6.8) at the scan rate of $60 \mathrm{mV} \mathrm{s}^{-1}$. The CNT electrode was prepared by drop casting of 5 $\mu \mathrm{L}$ of the $1 \mathrm{mg} \mathrm{mL}^{-1}$ MWCNTs (carboxylic acid functionalized) dispersion onto the cleaned surface of GC. CAT was immobilized using incubation in a solution of $1 \mathrm{kU} \mathrm{mL}^{-1}$ CAT in 0.1 M phosphate buffer solution ( $\mathrm{pH}$ 6.8) for $12 \mathrm{~h}$.

To investigate the effects of CAT on the voltammetry of the adsorbed GOx we compared results for three different GC/MWCNT/GOx electrode preparations. The first electrode was prepared using a purified GOx (purchased from BBI) with a GOx/CAT ratio $\geq 27500$, the second electrode was prepared using type II GOx from Sigma with a GOx/CAT ratio of 7.5, the third electrode was prepared using the purified GOx but with CAT added so the ratio of GOx/CAT was 7.5 to mimic the Sigma type II enzyme. In all cases the electrodes were treated in the same way with the GOx immobilized by incubating the electrodes in a solution of $1 \mathrm{kU} \mathrm{mL}^{-1} \mathrm{GOx}$ in $0.1 \mathrm{M}$ phosphate buffer solution ( $\mathrm{pH} 6.8$ ) for $12 \mathrm{~h}$.

The results are shown in Fig. 10. For the electrode prepared with the purified GOx the redox peaks are still present but are much smaller than those for the other two electrodes. Significantly, the redox peaks in the case of the type II enzyme and for the purified GOx mixed with CAT are very similar. From this we conclude that catalase, present as an impurity in many commercial GOx samples can contribute to the redox peaks seen in the voltammetry at around $-0.46 \mathrm{~V} v s$. SCE in $\mathrm{pH} 6.8$ solution. 


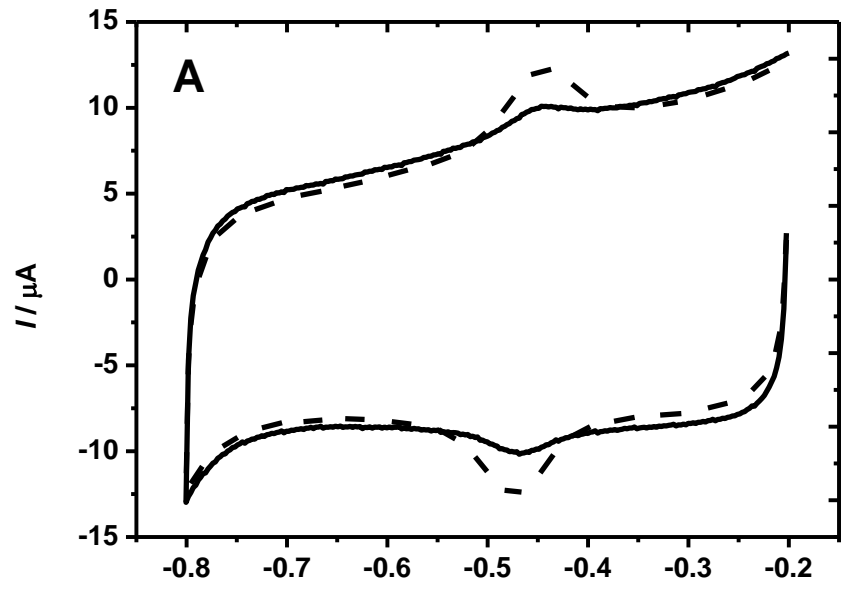

10. Cyclic Evs. SCE / V voltammograms

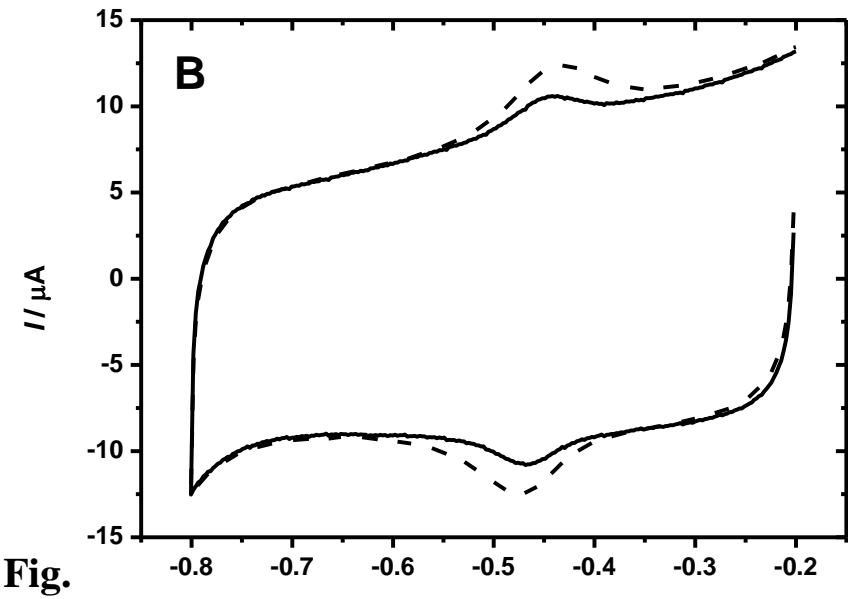

in $0.1 \quad \mathrm{M} \quad \boldsymbol{E}$ vs. SCE / V

deoxygenated PBS ( $\mathrm{pH}$ 6.8) at a scan rate of $60 \mathrm{mV} \mathrm{s}^{-1}$. A) For the GC/MWCNT/GOx electrode (prepared using pure GOx from BBI) (Solid line) and GC/MWCNT/GOx electrode (prepared using GOx from Sigma) (Dashed line). B) For the GC/MWCNT/GOx electrode (Solid line) and GC/MWCNT/GOx+CAT electrode (Dashed line).) The MWCNT electrode was prepared as in Fig. 2 using carboxylic acid functionalized MWCNTs. For the GC/MWCNT/GOx+CAT electrode The GOx+CAT mixture was immobilized using incubation in a solution of a 1:1 mixture of pure GOx $(1 \mathrm{kU})$ and CAT $(1 \mathrm{kU})$ in $1 \mathrm{~mL}$ of buffer.

\subsection{Drop casting GOx}

An alternative way to immobilise the GOx on the GC/MWCNT electrode is to drop cast a solution of the enzyme onto the surface rather than incubation of the electrode in a solution of GOx for $12 \mathrm{~h}$. In the drop casting experiments $5 \mu \mathrm{L}$ of GOx solution (5 U of enzyme) was placed onto the GC/MWCNT electrode and then left to dry in the refrigerator at $4^{\circ} \mathrm{C}$ for one hour before use. The results are shown in Fig. 11. For the type II GOx from Sigma the drop casting method still produces surface redox peaks around $-0.46 \mathrm{~V} v s$. SCE but they are somewhat less significant (associated redox charge $1.7 \mu \mathrm{C}$ ) than those from the $12 \mathrm{~h}$ incubation method (compare to Fig. 2). In contrast for the purified GOx from BBI the redox peaks produced by the drop casting method are very small (redox charge $0.46 \mu \mathrm{C}$ ).

These results strongly suggest that the surface redox peaks seen around $-0.46 \mathrm{~V}$ vs SCE are not associated with DET of GOx but rather arise from impurities in the enzyme solution and/or flavin that dissociates from the GOx. 


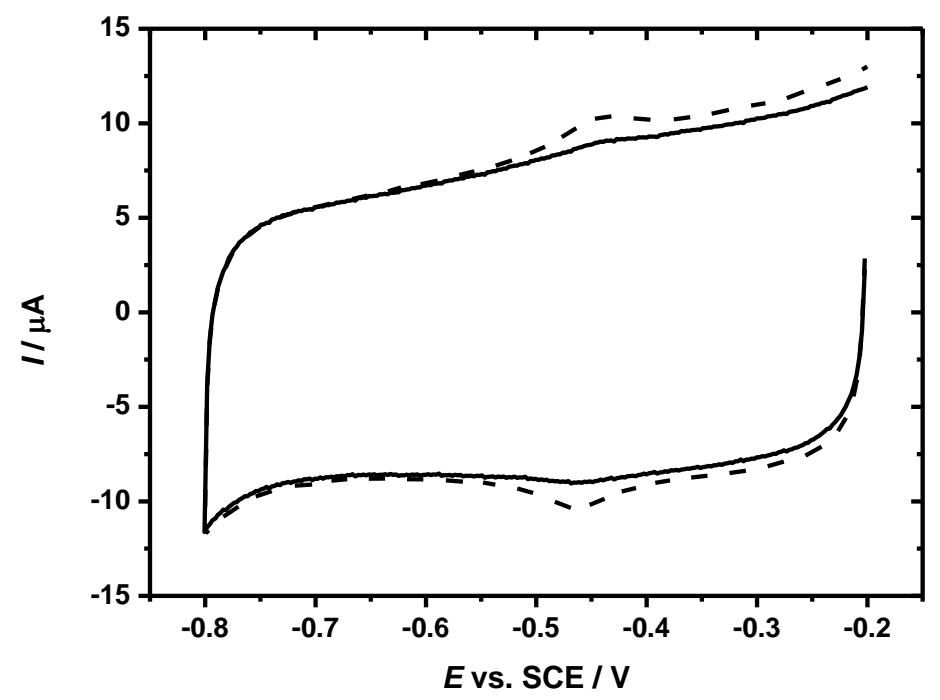

Fig. 11. Cyclic voltammograms in $0.1 \mathrm{M}$ deoxygenated PBS (pH 6.8) at a scan rate of $60 \mathrm{mV}$ $\mathrm{s}^{-1}$ for the GC / MWCNT / GOx electrode (using pure GOx) (Dashed line) and GC / MWCNT / GOx electrode (using GOx from Sigma) (Solid line). The MWCNT electrode was prepared by drop casting of $5 \mu \mathrm{L}$ of the $1 \mathrm{mg} \mathrm{mL}^{-1}$ MWCNTs (carboxylic acid functionalized) dispersion onto the cleaned surface of GC. GOx was immobilized by drop casting of $5 \mu \mathrm{L}(5$ U) GOx solution.

\subsection{Effect of solution $\mathrm{pH}$}

To investigate the origin of the surface redox peaks we have looked in detail at the $\mathrm{pH}$ dependence of the voltammetry. The two flavin redox groups in GOx are deeply buried within the protein $[6,7]$ and their environment should not be altered upon adsorption of the enzyme at the electrode surface unless there is a major disruption to the enzyme structure. Any such substantial disruption would, of necessity, be expected to significantly disrupt the catalytic activity of the enzyme. The redox potentials of flavins in flavoproteins are known to vary depending on the local environment around the flavin and the extent of solvent exposure [46]. Thus we expect the redox behaviour $\mathrm{pH}$ dependence of the flavin in the adsorbed GOx to be unchanged from that of the solution enzyme. The measurement of the redox potential of the flavin in GOx in solution is difficult because of the deeply buried nature of the flavin. Vogt [47] recently overcame this problem using UV/vis spectroelectrochemistry in a low volume cell with a range of redox mediators. In the following, we compare the results of our study of the $\mathrm{pH}$ dependence of the surface redox peaks to their recent results for GOx in solution. 
Fig. 12 (A) shows the effect of $\mathrm{pH}$ on the GC/MWCNT/GOx electrode in various buffer solutions ( $\mathrm{pH} 3-9)$. It can be seen that a pair of stable and well-defined redox peaks is observed in each $\mathrm{pH}$ solution. Both the $E_{\mathrm{pa}}$ and $E_{\mathrm{pc}}$ move to negative (or positive) potentials with increasing (or decreasing) $\mathrm{pH}$. The redox potentials shift by $\sim 50 \mathrm{mV}$ per $\mathrm{pH}$ unit.
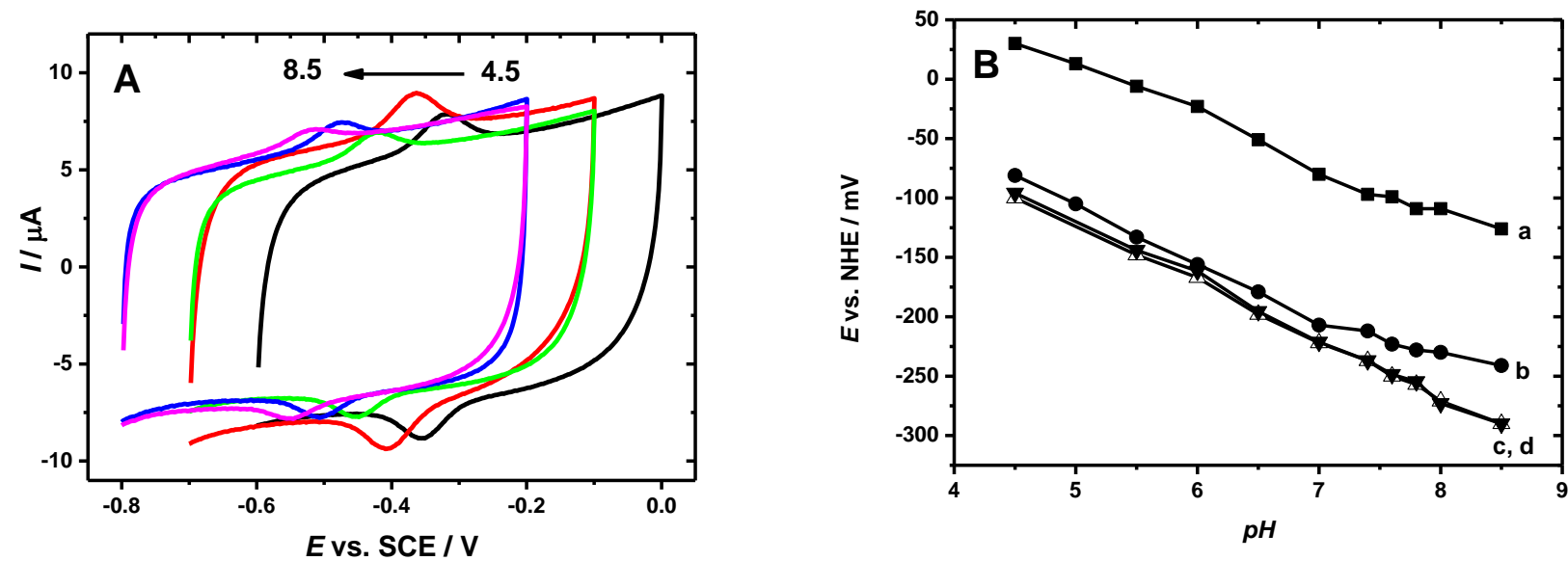

Fig. 12. (A) Cyclic voltammograms of a GC/MWCNT/GOx electrode in various deoxygenated solutions ( $\mathrm{pH} 4.5,5.5,7.6$, and 8.5) at $60 \mathrm{mV} \mathrm{s}^{-1}$. Measurements were performed in deoxygenated $0.1 \mathrm{M}$ buffers (sodium citrate, sodium phosphate, or tris (hydroxymethyl) aminomethane (TRIS) depending on $\mathrm{pH}$ ) with $0.1 \mathrm{M}$ potassium chloride and $5 \mathrm{mM}$ magnesium chloride. The GC/MWCNT/GOx electrode was prepared as in Fig. 2. (B) Redox potentials of (a) GOx and (b) FAD replotted from Vogt [47] compared with replicate experimental data (c,d) obtained from cyclic voltammetry of GC/MWCNT/GOx electrodes.

Fig. 12B shows a plot of the mid peak potentials for two replicate GC/MWCNT/GOx electrodes plotted as a function of $\mathrm{pH}$ (curves (c) and (d) in the Fig.). Also plotted in Fig. 12B for comparison are results for the $\mathrm{pH}$ dependence of the redox potentials of flavin and GOx in solution recently published by Vogt [47]. Comparing the results, we see that there is a significant difference between this experimental data and the redox potential for GOx in solution whereas the curves for the surface bound redox process and flavin in solution (curves b, c and d in Fig. 12B) are rather close. A similar shift in the redox potential of the enzyme bound FAD from that of the free FAD at $\mathrm{pH} 7$ was also reported by Liu [48] in experiments where the apo-enzyme was reconstituted around surface immobilised FAD.

There is a notable deviation between our data (curves $\mathrm{c}$ and $\mathrm{d}$ ) and the data for flavin in solution (curve b) above $\mathrm{pH}$ 7. For flavin in solution Vogt showed that the $\mathrm{pH}$ dependence changes from $-50 \mathrm{mV} \mathrm{pH}^{-1}$ below $\mathrm{pH} 7$ to $-27 \mathrm{mV} \mathrm{pH}^{-1}$ above $\mathrm{pH} 7$ [47]. This change 
corresponds to a $\mathrm{p} K_{\mathrm{a}}$ for the flavohydroquinone of around 6.8 in agreement with the literature [49]. The potentials and $\mathrm{pH}$ dependence observed in Fig. 12 for electrodes with adsorbed GOx (curves $\mathrm{c}$ and d) agree very well with literature data for flavin adsorbed on glassy carbon [50] and carbon nanotube electrodes [27]. Further, the observed shift in the $\mathrm{p} K_{\mathrm{a}}$ to values above 9 also agrees with the published results for adsorbed flavin and is the result of the interaction of the free flavin with the carbon surface.

Based on these results we conclude that the redox peaks seen for the surface bound redox couple cannot be taken as evidence for DET to the flavin in the active site of GOx. Rather they almost certainly arise from free FAD adsorbed directly on the electrode surface.

\subsection{Response to glucose}

The results presented so far have conclusively demonstrated, contrary to what is widely claimed in the literature, that the surface redox peaks seen on the MWCNT electrodes with adsorbed GOx are not due to direct electron transfer to the active site of the enzyme but, rather, are due to the adsorption of some impurity, possibly free flavin, onto the electrode surface. If this is the case how does the glucose response of these electrodes arise?

Fig. 13 shows a typical set of data for the voltammetry of the GC/MWCNT/GOx electrode with different concentrations of glucose. These results for D-glucose are representative of those reported in the literature by numerous authors for GOx adsorbed on MWCNTs, graphene and a variety of other nanomaterial electrode surfaces for which direct electron transfer to glucose oxidase has been claimed (see Table S1 for examples). 


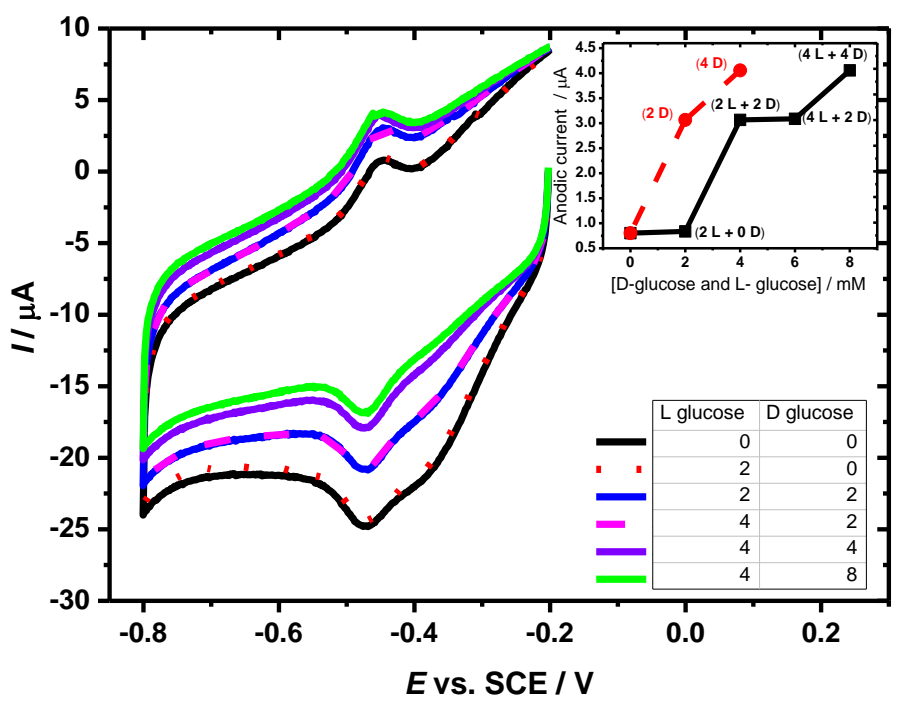

Fig. 13. Cyclic voltammograms showing oxygen reduction on a GC/MWCNT/GOx electrode in oxygen saturated $0.1 \mathrm{M}$ PBS pH 6.8 containing different concentration of $\mathrm{L}$ and D-glucose recorded at $60 \mathrm{mV} \mathrm{s}^{-1}$. The GC/MWCNT/GOx electrode was prepared as in Fig. 2 using pure carboxylic acid functionalized MWCNTs. Inset relative current for the CV experiments; total glucose (black solid line), D-glucose (red dashed line).

Fig. 13 also shows the effect of adding aliquots of L-glucose to the solution. The addition of L-glucose is an excellent control experiment to demonstrate whether the response actually arises from the enzymatic reaction or comes about in some other way although it is hardly ever used in the literature. In this case, we can see that whilst the current changes on addition of D-glucose additions of corresponding amounts of L-glucose have no effect. This rules out changes in the current because of purely physical effects (such as changes in solution viscosity etc. caused by addition of glucose) and non-specific electrochemical reactions, and clearly shows that the process is in some way enzyme catalysed.

Results of the type shown in Fig. 13 are often taken as evidence for DET for GOx but there are a number of serious problems with this interpretation. First, the current response corresponds to a decrease in the reduction current flowing at the electrode not the oxidation current expected to correspond to enzymatically catalysed electrochemical oxidation of glucose. Second, the surface redox peaks around $-0.46 \mathrm{~V} v s$. SCE are unchanged by addition of D-glucose with both oxidation and reduction peak clearly present throughout and simply moving with the changing background. Third, the change in current on addition of D-glucose starts at $-0.25 \mathrm{~V} v s$. SCE, well away from the potential of the surface redox peaks.

Key to understanding the response in Fig. 13 is the fact that there is oxygen dissolved in the solution. It is the reduction of oxygen that starts at $-0.25 \mathrm{~V} v s$. SCE at the MWCNT electrode. 
The change in current on addition of D-glucose corresponds to a decrease in the oxygen reduction current because the oxygen at the electrode surface is consumed by the enzyme catalysed reaction with glucose. The reactions occurring are

GOx $(\mathrm{FAD})+\beta$-D-glucose $\longrightarrow$ GOx $\left(\mathrm{FADH}_{2}\right)+\mathrm{D}$-glucono-1, 5-lactone

$\mathrm{GOx}\left(\mathrm{FADH}_{2}\right)+\mathrm{O}_{2} \longrightarrow \mathrm{GOx}(\mathrm{FAD})+\mathrm{H}_{2} \mathrm{O}_{2}$

On CNT electrodes the reduction of $\mathrm{O}_{2}$ proceeds to give $\mathrm{H}_{2} \mathrm{O}_{2}$ [51] and there is a large overpotential region over which the $\mathrm{H}_{2} \mathrm{O}_{2}$ is unreactive [52]. In those cases where metal nanoparticles are incorporated at the electrode (e.g. with added Au nanoparticles) it is possible to detect the $\mathrm{H}_{2} \mathrm{O}_{2}$ produced by the enzymatic reaction (see Table $\mathrm{S} 1$ for examples). Thus the results in Fig. 13 show that there is enzymatically active GOx adsorbed at the electrode surface but that it is not able to undergo DET at the electrode at any significant rate.

To further demonstrate this we now consider the oxygen reduction reaction at MWCNT electrodes.

\subsection{The oxygen reduction reaction at carbon nanotube electrodes}

The oxygen reduction reaction is very sensitive to impurities and there are many research papers that have highlighted the fact that carbon nanotubes, which are produced using metallic catalysts, contain residual metallic impurities [53-55]. This unavoidable presence of the metallic impurities can cause confusion when analysing the performance of the carbon nanotubes, especially in their application in biosensors and biofuel cells [56]. The removal of such residual metallic impurities is practically hard to achieve. Even after attempting several acid washing methods, the impurity concentration is in the range of several wt $\%[53,57]$.

We used two types of carbon nanotubes; multi-walled carbon nanotubes $(30 \pm 10 \mathrm{~nm}$ in diameter and 1 - $5 \mu \mathrm{m}$ in length from NanoLab Inc.), and carboxylic-acid-functionalized multi-walled carbon nanotubes (> 8\% carboxylic-acid-functionalized average, $9.5 \mathrm{~nm}$ in diameter and $1.5 \mu \mathrm{m}$ in length from Sigma-Aldrich) to illustrate this. According to the specification sheet given by the suppliers, the carboxylic-acid-functionalized carbon nanotubes should have higher purity than the other nanotubes. This is supported by the energy dispersive spectroscopy (EDS) spectra for the two, Fig. 14. 


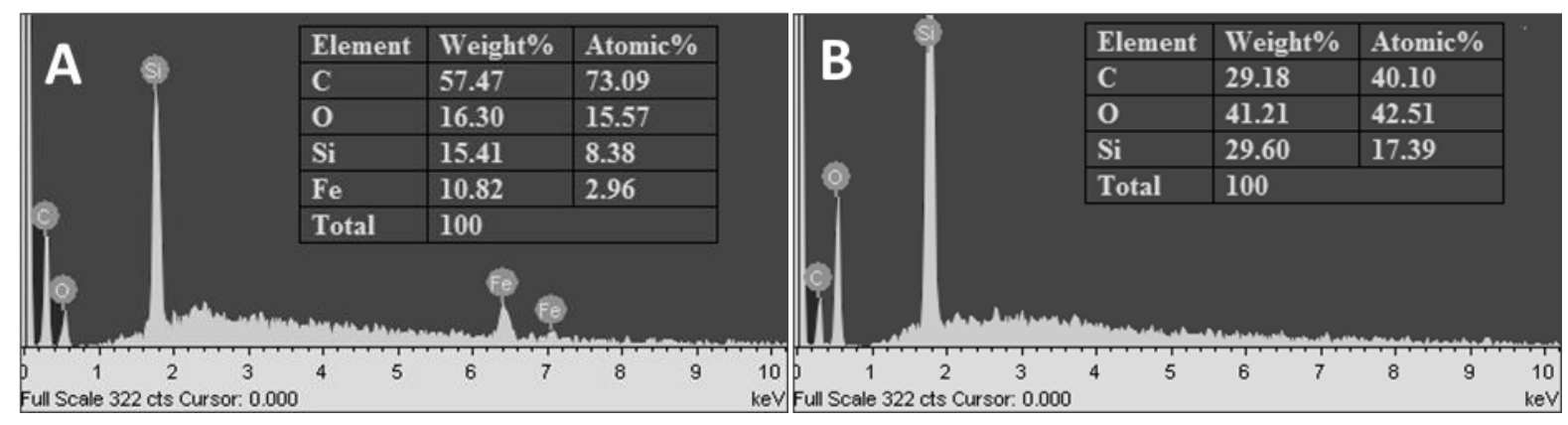

Fig. 14. EDS spectra of the MWCNT on the GC electrodes, magnification: 5000x, accelerating voltage: $20.0 \mathrm{kV}$. The GC/CNT electrodes were prepared by drop casting of 5 $\mu \mathrm{L}$ of $1 \mathrm{mg} \mathrm{mL}^{-1}$ MWCNT onto the cleaned surface of GC. A) MWCNTs from NanoLab Inc. B) carboxylic acid functionalized MWCNTs from Sigma-Aldrich.

For the MWCNTs from NanoLab Inc. Fig. 14A shows the presence of residual iron impurities, on the other hand, the carboxylic-acid-functionalized multi-walled carbon nanotubes from Sigma-Aldrich, Fig. 14B, show no evidence by EDS for metallic impurities but the $\mathrm{C}: \mathrm{O}$ ration is much larger, consistent with carboxylic acid functionalization.

The reduction of oxygen and the response to glucose were studied using GC electrodes modified with the two different types of MWCNTs. The results are shown in Fig. 15 and 16.
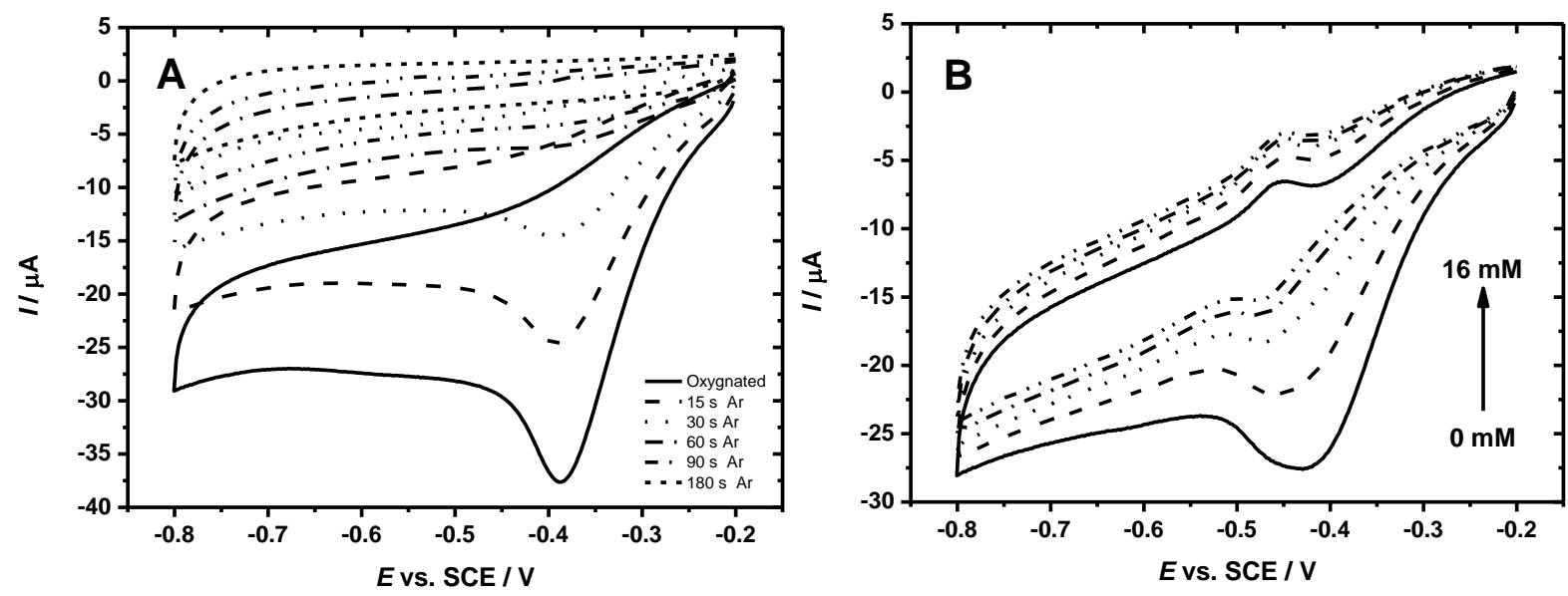

Fig. 15. Cyclic voltammograms recorded at $60 \mathrm{mV} \mathrm{s}^{-1}$ showing the response of (A) GC/MWCNT electrode in different oxygen concentrations and (B) GC/MWCNT/GOx in oxygen saturated $0.1 \mathrm{M}$ PBS pH 6.8 containing $0,4,8,12$ and $16 \mathrm{mM}$ of glucose. The GC/MWCNT/GOx was prepared as in Fig. 2 using MWCNTs from NanoLab, Inc. 

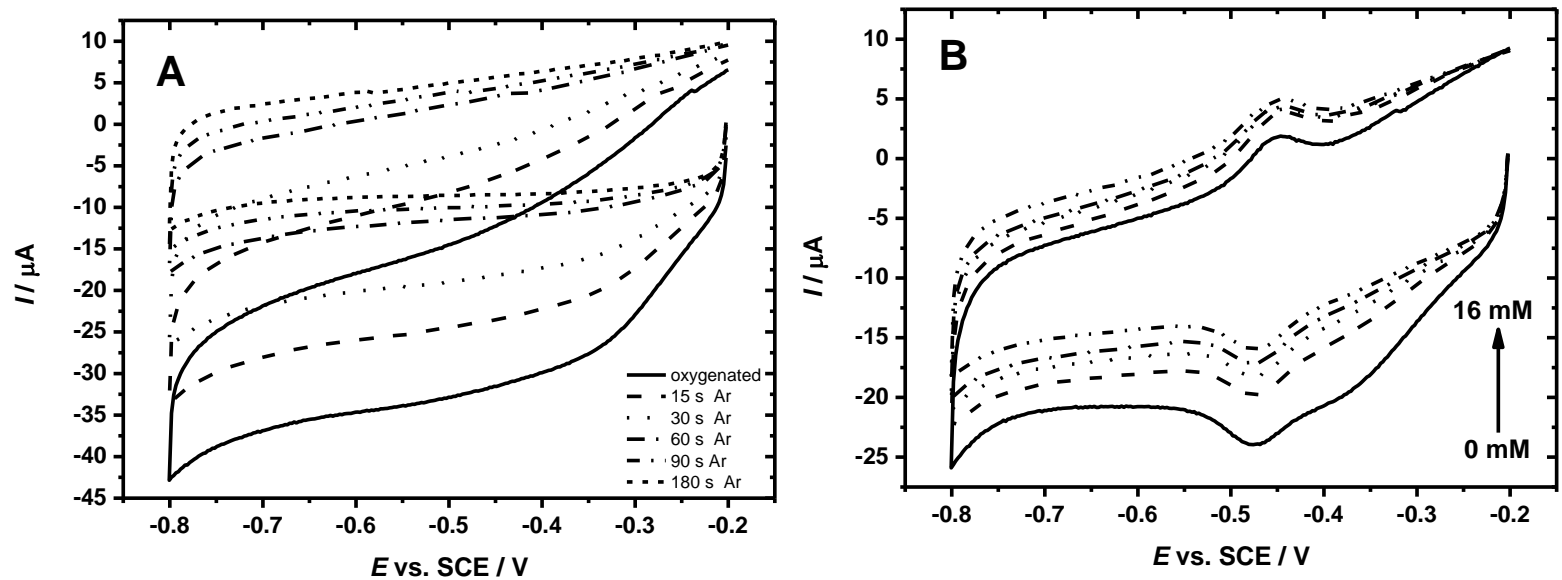

Fig. 16. Cyclic voltammograms recorded at $60 \mathrm{mV} \mathrm{s}^{-1}$ showing the response of (A) GC/MWCNT electrode in different oxygen concentrations and (B) GC/MWCNT/GOx in oxygen saturated $0.1 \mathrm{M}$ PBS pH 6.8 containing $0,4,8,12$ and $16 \mathrm{mM}$ of glucose. The GC/MWCNT/GOx was prepared as in Fig. 2 using carboxylic acid functionalized MWCNTs.

Oxygen reduction occurs in both cases starting from around $-0.25 \mathrm{~V}$ vs SCE. This current is clearly dependent on the concentration of dissolved oxygen in solution as it decreases with the increasing length of time that the solution is sparged with Ar, and eventually disappears when all the oxygen is removed from solution. Comparing the two electrodes, the currents are about the same in both cases but for the MWCNTs with the Fe impurity, Fig. 15A, there is an obvious peak in the current around $-0.4 \mathrm{~V}$ vs SCE which is not seen for the purified carboxylate modified MWCNTs. This is presumably because the impurity acts as an electrocatalyst for the oxygen reduction reaction [53]. It is worth noting that it is very difficult to prove that, even for purified MWCNTs, no traces of the metal catalyst used for the preparation of the nanotubes are remaining [55].

When we compare these results for oxygen reduction on the different MWCNT electrodes to those for the same electrodes with GOx adsorbed on the surface, Fig. 15 A and B and 16 A and $\mathrm{B}$, we see that the oxygen reduction current is less at the corresponding electrodes with adsorbed GOx indicating that the enzyme partially blocks the catalytic sites for oxygen reduction at the surface. We also can see that the onset potential and potential dependence of the reduction current is very similar in the corresponding cases (compare panels A and B in each case). 
Interestingly these results highlight the fact that the differences in performance of different GOx carbon nanotube electrode preparations are likely due to the different levels if impurity present in each case.

\section{Discussion}

\subsection{The implications of these results}

Our results show that the appearance of surface redox peaks around $-0.46 \mathrm{~V}$ vs SCE is not good evidence for DET to GOx but rather is explained by adsorption of impurities, most probably free flavin but also possibly catalase, onto the nanoelectrode material. The high surface area of the nanoelectrode material plays a role here in increasing the magnitude (charge) of these surface redox peaks. However, the enzyme is also adsorbed at the electrode surface and this adsorbed enzyme remains enzymatically active. Thus, the electrochemical response to glucose observed at potential cathodic of around $-0.25 \mathrm{~V} v s$. SCE is due to the decrease in dissolved oxygen concentration at the electrode surface brought about by the enzyme catalysed reaction of glucose with oxygen. This corresponds to a "first generation" glucose electrode behaviour rather that a "third generation" behaviour with DET to the GOx. Significantly, the behaviour of the system is dominated by the effects of impurities in both the enzyme preparation used, flavin and catalase in the GOx, and in the MWCNTs, Fe impurities that catalyse oxygen reduction. These impurities are ignored by many authors.

Our conclusions here are consistent with those of several authors who have questioned the evidence for DET of GOx. In particular Wang [58] concluded, in a study of GOx immobilized in chitosan on MWCNTs, that there was no evidence for DET even though they observed surface redox peaks and could demonstrate the presence of enzymatically active GOx at the electrode surface using a ferrocene mediator. They concluded that the redox peaks came from an adsorbed form of GOx that was enzymatically inactive although, since they used as-received GOx, it is likely that adsorbed free flavin was present. Goran [27] studied GOx adsorbed on carbon nanotubes and nitrogen-doped carbon nanotubes using type X-S GOx from Sigma-Aldrich. They concluded that adsorbed GOx was enzymatically active when a redox mediator (1,4-benzoquinone) was added or oxygen was present and that the surface redox peak was the result of flavin that was not enzymatically active. Wooten [59] used GOx (from Sigma-Aldrich) immobilized in chitosan on MWCNTs and found no 
evidence for DET. They concluded that the electroactive flavin seen in the voltammetry was not part of enzymatically active GOx.

Our results and conclusions are also in full agreement with the views expressed by Wilson in a recent editorial [60] that "native glucose oxidase does not undergo direct electron transfer". There is no reason to believe that similar effects are not equally predominant in the case of GOx electrodes fabricated with other nanomaterials such as graphene, gold nanoparticles or with various different "additives" such as chitosan or Nafion (see Table S1) supposedly to confer some additional advantage.

\subsection{Do MWCNTs show "special" properties?}

A question that arises from this work is to what extent carbon nanotubes show "special" properties with regard to their electrochemistry in applications in glucose electrodes. If we look at our results it is clear that there is nothing particular about the use of MWCNTs that improves the performance of the electrode beyond the fact that the MWCNT layer deposited on the glassy carbon supporting electrode provides a high real surface area, estimated in this case to be $14 \mathrm{~cm}^{2}$ corresponding to a roughness (real area/geometric area) of $\sim 200$. Coupled with this the background double layer charging current in the phosphate buffer solution at the glassy carbon electrode is much greater per unit real area $\left(100 \mu \mathrm{F} \mathrm{cm}{ }^{-2}\right)$ than that at the MWCNT surface $\left(8 \mu \mathrm{F} \mathrm{cm}^{-2}\right)$, Fig. 2. This difference can be attributed to the difference in the electronic structure of the two materials and the consequent difference in the density of states at the Fermi level $[61,62]$. In this sense the MWCNTs and carbon nanomaterials do have a "special" property but it nothing to do with their ability to transfer electrons to/from native GOx.

\subsection{Evidence for real DET with GOx}

Here we have concentrated on the great majority of papers that claim DET for GOx based on the redox peaks seen around $-0.46 \mathrm{vs}$. SCE and the change in current at potentials cathodic of $-0.25 \mathrm{~V} v s$. SCE. However, there are a very small number of examples where catalytic oxidation of glucose appears to occur providing some evidence for DET. 
For example Jiang [63] immobilized GOx at a gold electrode using 3,3'-bithiobissulfosuccinimidylpropionate (DTSSP). The enzyme was first reacted with DTSSP overnight to form an amide bond between lysine residues on the enzyme and the DTSSP ester group and then the disulfide of the DTSSP was reductively cleaved on the gold surface to form an immobilized monolayer of enzyme. They observed surface redox peaks for the modified electrode at ca. $-282 \mathrm{mV} v s . \mathrm{Ag} / \mathrm{AgCl}$ in solution at $\mathrm{pH} 6.3$. Interestingly this is $\sim 80 \mathrm{mV}$ positive of the potential for adsorbed flavin although not as positive as the values expected for flavin in GOx (see Fig. 12B) suggesting that the immobilisation may have distorted the enzyme structure to make the flavin more accessible. Using this electrode they observed catalytic currents for glucose oxidation at $-200 \mathrm{mV} v$. $\mathrm{Ag} / \mathrm{AgCl}$.

Both Demin [64] and Courjean [65] studied deglycosylated GOx (dGOx). In the case of Demin [64] they used a His tag at the C-terminus to immobilize the non-glycosylated GOx at a Cu-NTA modified glassy carbon electrode. They found a $104 \mathrm{mV}$ positive shift in the redox potential for the dGOx as compared to flavin adsorbed at the same electrode, however, because they used a solid state $\mathrm{Ag} / \mathrm{AgCl}$ reference electrode direct comparision of the redox potetials to those in Fig. 12B is not possible. Although they only report very preliminary data for the response to glucose they do show what appears to be catalytic activity for the reduction of oxygen. Courjean [65] used purified, nearly fully deglycosylated GOx adsorbed on a glassy carbon electrode. In this case they found redox peaks for the adsorbed dGOx at $490 \mathrm{mV}$ vs. $\mathrm{Ag} / \mathrm{AgCl}$ in $\mathrm{pH} 7.4$ solution, very close to the value expected for adsorbed flavin (see Fig. 12B). Using this electrode they observe a strong catalytic response to glucose with a half wave potential of ca. $-400 \mathrm{mV}$.

Three other papers report evidence for catalytic oxidation of glucose using electrodes with adsorbed GOx. Grosse [66] used purified GOx from Sigma-Aldrich with reduced graphene oxide (rGO) and MWCNTs. They observe a surface redox couple at $-463 \mathrm{mV}$ vs. $\mathrm{Ag} / \mathrm{AgCl}$ at $\mathrm{pH} 7.4$ (this is in the expected range for adsorbed flavin, see Fig. 12B) and only a very small increase in oxidation current upon addition of $150 \mathrm{mM}$ glucose. Wang [67] used as received GOx from Sigma-Aldrich adsorbed inside poly(aniline) nanotubes grown in anodic alumina. They found a surface redox peaks at $-405 \mathrm{mV}$ vs. SCE in $\mathrm{pH} 5.5$ solution (again in the expected range for adsorbed flavin, see Fig. 12B) and a very large, apparently catalytic, response to addition of $5 \mathrm{mM}$ glucose (Fig 4 in their paper) with a $\mathrm{pH}$ optimum at $\mathrm{pH} 5.5$. Rafighi [68] used type VII GOx from Sigma-Aldrich immobilized on a graphenepolyethyleneimine-gold nanoparticle electrode. They observe surface redox peaks at $-380 \mathrm{mV}$ 
vs. $\mathrm{Ag} / \mathrm{AgCl}$ sat. $\mathrm{KCl}$ in $\mathrm{pH} 7.0$ solution, close to the expected value for adsorbed flavin (see Fig. 12B). They see very clear catalytic responses to glucose at around $-380 \mathrm{mV}$ (their Fig 6) increasing with increasing additions of glucose and then saturating at around $2 \mathrm{mM}$ glucose. It is difficult to rationalise these results in view if the rest of the literature, for example given in Table S1, and the experimental results presented earlier.

Finally, in this section we should mention those examples in which the apoenzyme has been reconstituted around a flavin covalently attached to the electrode surface. For example Liu [48] reconstituted apoGOx around flavin covalently attached to the ends of SWCNTs assembled vertically by bonding though a thiol on a gold electrode. They found that for the free flavin the surface redox potential was $-423 \mathrm{mV} v$ s. $\mathrm{Ag} / \mathrm{AgCl}$ in $\mathrm{pH} 7.0$ solution and that this shifted to $-380 \mathrm{mV}$ upon reconstitution into the GOx. Compared to the results in Fig. 12B the value for the free flavin is in good agreement with our results. The value for the reconstituted immobilized GOx is somewhat negative of the enzyme solution value (by around $100 \mathrm{mV}$ ) but this may reflect the perturbation to the structure expected from assembly about the SWCNT. No results for glucose response were given in this paper so it is not clear if the reconstituted enzyme was active.

\subsection{What evidence is required to demonstrate DET?}

We conclude this discussion by considering what experimental evidence would be really necessary in order to demonstrate DET for GOx or, more generally, for any redox enzyme. First, it is important to realize that, because of their biological function, some redox enzymes have exposed redox centres or defined redox pathways that allow the enzyme to interact and transfer electrons to/from other large biological redox species such as cytochrome $c$ or biopolymers such as lignin [46]. In these cases direct electron transfer to electrode surfaces is expected to be possible if the surface is properly designed. Examples include laccase, horseradish peroxidase, bilirubin oxidase, and cellobiose dehydrogenase. On the other hand some redox enzymes, like GOx, have evolved to avoid indiscriminate redox reactions in the biological milieu and as such are expected to be very difficult, if not impossible in their native form to undergo DET. In these cases it is wise to start from a sceptical position when considering evidence of DET.

Second, it is clear that purification of the enzyme is essential. As supplied, commercial enzyme samples are, in general, far from pure and often contain added reagents to stabilise the material. Purification is essential since these impurities can have a significant effect on 
the electrochemistry, see for example the work on GOx by Gao [69], and because these impurities can be adsorbed and concentrated on high surface nanomaterials, as with FAD here, and thus dominate the electrochemical response.

Third, it is important to look for the "signature" for the electrocatalytic response upon addition of the substrate and to look at the magnitudes of these catalytic currents and their substrate concentration dependence. In the case of GOx the oxidation of glucose should be seen at potentials starting from the redox potential of the bound flavin accompanied by the disappearance of the corresponding flavin reduction peak.

Fourth, it is advisable to carry our control experiments to ensure that the enzyme selectivity is maintained. In the case of GOx this is readily achieved using L-glucose which is not a substrate and can therefore be used to check for any non-enzyme specific effects, such as direct, non-enzyme catalysed oxidation of the glucose, that might occur. Again for high surface area nanoelectrode materials this can be important since even very inefficient direct oxidation could lead to a measurable signal for high $(>10 \mathrm{mM})$ glucose concentrations. An alternative strategy here is to use an inhibitor for the enzyme, if available, to show that upon addition of the inhibitor the electrocatalytic response is clearly decreased as expected.

Finally, it is very useful to carry out experiments using different substrates with different enzyme reaction kinetics since this is an excellent way to test whether the enzymatic activity and selectivity is preserved or whether the structure of the enzyme has undergone significant perturbation. For GOx this can be easily achieved by investigating the response to other substrates such as 2-deoxy-D-glucose and D-mannose $[8,70]$.

These same general principle can be equally well applied to studies of other redox enzymes.

\section{Conclusions}

In this paper we have demonstrated that the evidence provided in the literature for the vast majority of cases in support of direct electron transfer to glucose oxidase at electrodes made for various nanomaterials, but particularly carbon nanotubes and graphene of various forms, is unconvincing. We have shown that the surface redox peaks usually observed in these cases are due to free, adsorbed flavin and not due, as claimed, to DET to flavin within the enzyme. In most cases this free flavin comes predominantly from impurities present in the commercial enzyme when it is used without purification. We have also shown that catalase, also present in significant amounts in commonly use commercial sources of GOx, is also a concern. 
Our results show that the commonly reported response to glucose seen in the presence of oxygen is due to the consumption of oxygen by adsorbed, enzymatically active, but electrochemically inactive, GOx present at the electrode surface and that metal impurities present in the MWCNTs play a significant role in determining the voltammetry associated with the oxygen reduction. In this respect it is ironic that the commonly reported results that claim DET for GOx, as given in Table S1, are largely determined by impurities.

Thus, our clear conclusion is that there is no evidence for direct electron transfer to native glucose oxidase.

\section{Acknowledgements}

FAA acknowledges financial support from the Ministry of Higher Education and Scientific Research of Iraq. PNB gratefully acknowledges receipt of a Wolfson Research Merit Award.

\section{References}

[1] L.C. Clark, C. Lyons, Electrode systems for continuous monitoring in cardiovascular surgery, Ann. N. Y. Acad. Sci. 102 (1962) 29-45.

[2] A.P.F. Turner, I. Karube, G.S. Wilson, Biosensors. Fundamentals and Applications, OUP, Oxford, 1987.

[3] W.J. Albery, P.N. Bartlett, A.E. Cass, D.H. Craston, B.G.D. Haggett, "Electrochemical sensors theory and experiment, J. Chem. Soc., Faraday Trans, I 82 (1986) 1033-50.

[4] A.E.G. Cass, G. Davis, G.D. Francis, H.A.O. Hill, W.J. Aston, I.J. Higgins, E.V. Plotkin, L.D.L. Scott, A.P.F. Turner, Ferrocene-mediated enzyme electrode for amperometric determination of glucose, Anal. Chem. 56 (1984) 667-71.

[5] R. Wilson, A.P.F. Turner, Glucose oxidase: an ideal enzyme, Biosens. Bioelectron. 7 (1992) 165-85.

[6] H.J. Hecht, D. Schomburg, H. Kalisz, R.D. Schmid, The 3D structure of glucose oxidase from Aspergillus niger. Implications for the use of GOD as a biosensor enzyme, Biosens. Bioelectron. 8 (1993) 197-203.

[7] H.J. Hecht, H. Kalisz, J. Hendle, R.D. Schmid, D. Schomburg, Crystal structure of glucose oxidase from Aspergilus niger, J. Mol. Biol. 229 (1993) 153-72.

[8] J. Raba, H.A. Mottola, Glucose oxidase as an analytical reagent, Crit. Rev. Anal. Chem. 25 (1995) 1-42.

[9] J.H. Pazur, K. Kleppe, E.M. Balls, The glycoprotein nature of some fungal carbohydrases, Arch. Biochem. Biophys. 103 (1963) 515-8.

[10] B.E.P. Swoboda, V. Massey, Purification and properties of the glucose oxidase from Aspergillus niger, J. Biol. Chem. 240 (1965) 2209-15.

[11] H.M. Kalisz, H.-J. Hecht, D. Schomburg, R.D. Schmid, Effects of carbohydrate depletion on the st:ucture, stability and activity of glucose oxidase from Aspergillus niger, Biochim. Biophys. Acta 1080 (1991) 138-42.

[12] H.B. Gray, J.R. Winkler, Electron tunneling through proteins Quart. Rev. Biophys. 36 (2003) 34172.

[13] C.C. Moser, J.M. Keske, K. Warncke, R.S. Farid, P.L. Dutton, Nature of biological electron transfer, Nature 355 (1992) 796-802. 
[14] R.A. Marcus, N. Sutin, Electron transfers in chemistry and biology Biochim. Biophys. Acta 811 (1985) 265-322.

[15] K.A. M., J. Ulstrup, Electron Transfer in Chemistry and Biology. An Introduction to the Theory, John Wiley \& Sons Ltd., Chichester, 1999.

[16] Y. Degani, A. Heller, Direct electrical communication between chemically modified enzymes and metal electrodes. 1. Electron transfer from glucose oxidase via electron relays bound covalently to the enzyme, J. Phys. Chem. 91 (1987) 1285-9.

[17] L. Agui, P. Yanez-Sedeno, J.M. Pingarron, Role of carbon nanotubes in electroanalytical chemistry - A review, Anal. Chim. Acta 622 (2008) 11-47.

[18] C. Chen, Q. Xie, D. Yang, H. Xiao, Y. Fu, Y. Tan, S. Yao, Recent advances in electrochemical glucose biosensors: a review, RSC Advances 3 (2013) 4473-91.

[19] P. Das, M. Das, S.R. Chinnadayyala, I.M. Singha, P. Goswami, Recent advances on developing 3rd generation enzyme electrode for biosensor applications, Biosens. Bioelectron. 79 (2016) 386-97.

[20] A. Harper, M.R. Anderson, Electrochemical glucose sensors - developments using electrostatic assembly and carbon nanotubes for biosensor construction, Sensors 10 (2010) 8248-74.

[21] J.H.T. Luong, J.D. Glennon, A. Gedanken, S.K. Vashist, Achievement and assessment of direct electron transfer of glucose oxidase in electrochemical biosensing using carbon nanotubes, graphene, and their nanocomposites, Microchim. Acta 184 (2017) 369-88.

[22] A. Peigney, C. Laurent, E. Flahaut, R.R. Bacsa, A. Rousset, Specific surface area of carbon nanotubes and bundles of carbon nanotubes, Carbon 39 (2001) 507-14.

[23] E. Laviron, General expression of the linear potential sweep voltammogram in the case of diffusionless electrochemical systems, J. Electroanal. Chem. 101 (1979) 19-28.

[24] L. Roullier, E. Laviron, Effect of uncompensated ohmic drop in surface linear potential sweep voltammetry: Application to the determination of surface rate constants, J. Electroanal. Chem. 157 (1983) 193-203.

[25] M.J. Honeychurch, G.A. Rechnitz, Voltammetry of adsorbed molecules. Part 2: Irreversible redox systems, Electroanalysis 10 (1998) 453-7.

[26] M.J. Honeychurch, G.A. Rechnitz, Voltammetry of adsorbed molecules. Part 1: Reversible redox systems, Electroanalysis 10 (1998) 285-93.

[27] J.M. Goran, S.M. Mantilla, K.J. Stevenson, Influence of surface adsorption on the interfacial electron transfer of flavin adenine dinucleotide and glucose oxidase at carbon nanotube and nitrogen-doped carbon nanotube electrodes, Anal. Chem. 85 (2013) 1571-81.

[28] M.J. Honeychurch, Effect of the interfacial potential distribution on the measurement of the rate constant for electron transfer between electrodes and redox adsorbates, Langmuir 14 (1998) 6291-6.

[29] C.X. Cai, J. Chen, T.H. Lu, Direct electron transfer of glucose oxidase on the carbon nanotube electrode, Sci. China Ser. B 47 (2004) 113-9.

[30] C.X. Cai, J. Chen, Direct electron transfer of glucose oxidase promoted by carbon nanotubes, Anal. Biochem. 332 (2004) 75-83.

[31] R.M. Ianniello, T.J. Lindsay, A.M. Yacynych, Differential pulse voltammetric study of direct electron transfer in glucose oxidase chemically modified electrodes, Anal. Chem. 54 (1982) 1098-101. [32] O. Blumenfeld, J. Léonie, G.E. Perlmann, The effect of guanidine hydrochloride on crystalline pepsin, J. Biol. Chem. 235 (1960) 379-82.

[33] X.M. He, D.C. Carter, Atomic structure and chemistry of human serum albumin, Nature 358 (1992) 209-15.

[34] R.E. Holt, T.M. Cotton, Free flavin interference in surface enhanced resonance Ramanspectroscopy of glucose oxidase, J. Amer. Chem. Soc. 109 (1987) 1841-5.

[35] J.E. Frew, H.A.O. Hill, Direct and indirect electron transfer between electrodes and redox proteins, Eur. J. Biochem. 172 (1988) 261-9. 
[36] K. Szot, M. Joensson-Niedziolka, E. Rozniecka, F. Marken, M. Opallo, Direct electrochemistry of adsorbed proteins and bioelectrocatalysis at film electrode prepared from oppositely charged carbon nanoparticles, Electrochim. Acta 89 (2013) 132-8.

[37] B.E.P. Swoboda, The relationship between molecular conformation and the binding of flavinadenine dinucleotide in glucose oxidase, Biochim. Biophys. Acta 175 (1969) 365-79.

[38] S.B. Bankar, M.V. Bule, R.S. Singhal, L. Ananthanarayan, Glucose oxidase - An overview, Biotechnol. Adv. 27 (2009) 489-501.

[39] G.R. Schonbaum, B. Chance, Catalase, in: P.D. Boyer (Ed) The Enzymes, Academic Press, New York, 976, pp. 363-408.

[40] M.R. Murthy, T.J. Reid , A. Sicignano, N. Tanaka, M.G. Rossmann, Structure of beef liver catalase, J. Mol. Biol. 152 (1981) 465-99.

[41] I. Fita, A.M. Silva, M.R.N. Murthy, M.G. Rossmann, The refined structure of beef liver catalase at 2.5 Å resolution, Acta Crystallogr. Sect. B: Struct. Sci. 42 (1986) 497-575.

[42] P.A. Prakash, U. Yogeswaran, S.-M. Chen, A review on direct electrochemistry of catalase for electrochemical sensors, Sensors 9 (2009) 1821-44.

[43] H.-J. Jiang, H. Yang, D.L. Akins, Direct electrochemistry and electrocatalysis of catalase immobilized on a SWNT-nanocomposite film, J. Electroanal. Chem. 623 (2008) 181-6.

[44] A.T.E. Vilian, S.-M. Chen, B.-S. Lou, A simple strategy for the immobilization of catalase on multiwalled carbon nanotube/poly(L-lysine) biocomposite for the detection of $\mathrm{H}_{2} \mathrm{O}_{2}$ and iodate, Biosens. Bioelectron. 61 (2014) 639-47.

[45] Z. Zhang, S. Chouchane, R.S. Magliozzo, J.F. Rusling, Direct voltammetry and catalysis with Mycobacterium tuberculosis catalase-peroxidase, peroxidases, and catalase in lipid films, Anal. Chem. 74 (2002) 163-70.

[46] P.N. Bartlett, Bioenergetics and biological electron transport, in: P.N. Bartlett (Ed) Bioelectrochemistry: Fundamentals, Experimental Techniqies and Applications, John Wiley \& Sons, Chichester, 2008, pp. 1-38.

[47] S. Vogt, M. Schneider, H. Schafer-Eberwein, G. Noll, Determination of the pH dependent redox potential of glucose oxidase by spectroelectrochemistry, Anal. Chem. (2014).

[48] J.Q. Liu, A. Chou, W. Rahmat, M.N. Paddon-Row, J.J. Gooding, Achieving direct electrical connection to glucose oxidase using aligned single walled carbon nanotube arrays, Electroanalysis 17 (2005) 38-46.

[49] H.J. Lowe, W.M. Clark, Studies on oxidation-reduction XXIV. Oxidation-reduction potentials of flavin adenine dinucleotide, J. Biol. Chem. 221 (1956) 983-92.

[50] H. Wei, S. Omonovic, Interaction of flavin adenine nucleotide (FAD) with a glassy carbon electrode surface, Chem. Biodiversity 5 (2008) 1622-38.

[51] J.C. Byers, A.G. Güell, P.R. Unwin, Nanoscale electrocatalysis: visualizing oxygen reduction at pristine, kinked, and oxidized sites on individual carbon nanotubes, J. Am. Chem. Soc. 136 (2014) 11252-5.

[52] J.M. Goran, E.N.H. Phan, C.A. Favela, K.J. Stevenson, $\mathrm{H}_{2} \mathrm{O}_{2}$ detection at carbon nanotubes and nitrogen-doped carbon nanotubes: oxidation, reduction, or disproportionation?

, Anal. Chem. 87 (2015) 5989-96.

[53] L. Wang, M. Pumera, Residual metallic impurities within carbon nanotubes play a dominant role in supposedly "metal-free" oxygen reduction reactions, Chem. Commun. 50 (2014) 12662-4.

[54] J.H. Lehman, M. Terrones, E. Mansfield, K.E. Hurst, V. Meunier, Evaluating the characteristics of multiwall carbon nanotubes, Carbon 49 (2011) 2581-602.

[55] P.A. Mello, L.F. Rodrigues, M.A.G. Nunes, J.C.P. Mattos, E.I. Mueller, V.L. Dressler, E.M.M. Flores, Determination of metal impurities in carbon nanotubes by direct solid sampling electrothermal atomic absorption spectrometry, J. Braz. Chem. Soc. 22 (2011) 1040-U62.

[56] Y. Wenrong, K.R. Ratinac, S.P. Ringer, P. Thordarson, J.J. Gooding, F. Braet, Carbon nanomaterials in biosensors: should you use nanotubes or graphene?, Angew. Chem., Int. Ed. 49 (2010) 2114-38. 
[57] Y. Wang, H. Shan, R.H. Hauge, M. Pasquali, R.E. Smalley, A highly selective, one-pot purification method for single-walled carbon nanotubes, J. Phys. Chem. B 111 (2007) 1249-52.

[58] Y. Wang, Y. Yao, Direct electron transfer of glucose oxidase promoted by carbon nanotubes is without value in certain mediator-free applications, Microchim. Acta 176 (2012) 271-7.

[59] M. Wooten, S. Karra, M. Zhang, W. Gorski, On the direct electron transfer, sensing, and ezyme activity in the glucose oxidase/carbon nanotubes system, Anal. Chem. 86 (2014) 752-7.

[60] G.S. Wilson, Native glucose oxidase does not undergo direct electron transfer, Biosens. Bioelectron. 82 (2016) vi-vii.

[61] R.L. McCreery, M.T. McDermott, Comment on Electrochemical Kinetics at Ordered Graphite Electrodes, Analytical Chemistry 84 (2012) 2602-5.

[62] R.L. McCreery, Advanced carbon electrode materials for molecular electrochemistry, Chemical Reviews 108 (2008) 2646-87.

[63] L. Jiang, C.J. McNeil, J.M. Cooper, Direct flectron transfer reactions of glucose oxidase immobilised at a self -assembled mono layer, Chem. Commun. (1995) 1293-5.

[64] S. Demin, E.A.H. Hall, Breaking the barrier to fast electron transfer, Bioelectrochemistry 76 (2009) 19-27.

[65] O. Courjean, F. Gao, N. Mano, Deglycosylation of glucose oxidase for direct and efficient glucose electrooxidation on a glassy carbon electrode, Angew. Chem. (2009) 6011 -3.

[66] W. Grosse, J. Champavert, S. Gambhir, G.G. Wallace, S.E. Moulton, Aqueous dispersions of reduced graphene oxide and multi wall carbon nanotubes for enhanced glucose oxidase bioelectrode performance, Carbon (2013) 467-75.

[67] Z. Wang, S. Liu, P. Wu, C. Cai, Detection of glucose based on direct electron transfer reaction of glucose oxidase immobilized on highly ordered polyaniline nanotubes, Anal. Chem. 81 (2009) 163845.

[68] P. Rafighi, M. Tavahodi, B. Haghighi, Fabrication of a third-generation glucose biosensor using graphene-polyethyleneimine-gold nanoparticles hybrid, Sens. Actuat. B 232 (2016) 454-61.

[69] F. Gao, O. Courjean, N. Mano, An improved glucose $/ \mathrm{O}_{2}$ membrane-less biofuel cell through glucose oxidase purification, Biosensors \& Bioelectronics 25 (2009) 356-61.

[70] H.J. Bright, M. Appleby, The $\mathrm{pH}$ dependence of the individual steps in the glucose oxidase reaction, J. Biol. Chem. 244 (1969) 3625-31334. 